\title{
The NLP Toxin Family in Phytophthora sojae Includes Rapidly Evolving Groups That Lack Necrosis-Inducing Activity
}

\author{
Suomeng Dong, ${ }^{1,3}$ Guanghui Kong, ${ }^{1}$ Dinah Qutob, ${ }^{2}$ Xiaoli Yu, ${ }^{1}$ Junli Tang, ${ }^{1}$ Jixiong Kang, ${ }^{1}$ Tingting Dai, ${ }^{1}$ \\ Hai Wang, ${ }^{1}$ Mark Gijzen, ${ }^{2}$ and Yuanchao Wang ${ }^{1,3}$ \\ ${ }^{1}$ College of Plant Protection, Nanjing Agricultural University, Nanjing 210095, China; ${ }^{2}$ Agriculture and Agri-Food Canada, \\ London, ON, N5V 4T3, Canada; ${ }^{3}$ Key Laboratory of Integrated Management of Crop Diseases and Pests (Nanjing Agricultural \\ University), Ministry of Education, Nanjing 210095, China
}

Submitted 30 January 2012. Accepted 29 February 2012.

Necrosis- and ethylene-inducing-like proteins (NLP) are widely distributed in eukaryotic and prokaryotic plant pathogens and are considered to be important virulence factors. We identified, in total, 70 potential Phytophthora sojae NLP genes but 37 were designated as pseudogenes. Sequence alignment of the remaining 33 NLP delineated six groups. Three of these groups include proteins with an intact heptapeptide (Gly-His-Arg-His-Asp-Trp-Glu) motif, which is important for necrosis-inducing activity, whereas the motif is not conserved in the other groups. In total, 19 representative NLP genes were assessed for necrosis-inducing activity by heterologous expression in Nicotiana benthamiana. Surprisingly, only eight genes triggered cell death. The expression of the NLP genes in $P$. sojae was examined, distinguishing 20 expressed and 13 nonexpressed NLP genes. Real-time reverse-transcriptase polymerase chain reaction results indicate that most NLP are highly expressed during cyst germination and infection stages. Amino acid substitution ratios $(\mathrm{Ka} / \mathrm{Ks})$ of $33 \mathrm{NLP}$ sequences from four different $P$. sojae strains resulted in identification of positive selection sites in a distinct NLP group. Overall, our study indicates that expansion and pseudogenization of the $P$. sojae NLP family results from an ongoing birth-and-death process, and that varying patterns of expression, necrosis-inducing activity, and positive selection suggest that NLP have diversified in function.

The genus Phytophthora comprises a group of filamentous fungus-like organisms that are known as notorious plant pathogens. Phytophthora infestans causes late blight disease and was responsible for the Irish potato famine, while the root rot pathogen $P$. sojae inflicts losses to global soybean production (Haas et al. 2009; Tyler et al. 2006). According to current knowledge, species of Phytophthora are hemibiotrophic pathogens that manipulate host cell death processes to establish a

M. Gijzen and Y. Wang contributed equally to this work.

Corresponding authors: Y. Wang, E-mail: wangyc@njau.edu.cn and M. Gijzen, E-mail: Mark.Gijzen@agr.gc.ca

* The $\boldsymbol{e}$-Xtra logo stands for "electronic extra" and indicates that four supplementary figures and five supplementary tables are published online.

This article is in the public domain and not copyrightable. It may be freely reprinted with customary crediting of the source. The American Phytopathological Society, 2012. successful colonization. By secreting an arsenal of effector molecules into the apoplast and cytoplasm of host cells, Phytophthora spp. may suppress or accelerate the death of plant cells in order to foster disease (Kamoun 2006). Particular hosttargeted effectors known as avirulence (Avr) factors can also limit the pathogen by triggering immunity in plants with appropriate resistance $(R)$ genes (Jones and Dangl 2006).

The known Phytophthora spp. Avr factors encode RxLR effectors that trigger plant cell death through their interaction with host $R$ genes. These include Avr3a, Avrblb1, Avrblb2, Avr2, and Avr4, secreted by P. infestans (Armstrong et al. 2005; Gilroy et al. 2011; Oh et al. 2009; van Poppel et al. 2008; Vleeshouwers et al. 2008); and Avr1a, Avr1b, Avr3a/5, Avr3c, Avr3b, and Avr4/6 from P. sojae (Dong et al. 2009, 2011a and b; Dou et al. 2008, 2010; Qutob et al. 2009; Shan et al. 2004). Recently, large-scale screening work on the $P$. infestans and $P$. sojae RxLR members identified a number of effectors that are able to induce or to block plant cell death $(\mathrm{Oh}$ et al. 2009; Wang et al. 2011). In addition to RxLR effectors, past research has uncovered a variety of secreted proteins from Phytophthora spp. that are capable of causing plant cell death. These include elicitins, phytotoxic proteins like those first described in the $P$. cactorum-Fragaria interaction (PcF-like), crinkling- and necrosis-inducing proteins (CRN), cellulosebinding elicitor and lectin-like proteins, and necrosis- and ethylene-inducing-like proteins (NLP) (Fellbrich et al. 2002; Gaulin et al. 2002, 2006; Kamoun et al. 1997; Liu et al. 2005; Qutob et al. 2002; Torto et al. 2003).

The NLP are a group of proteins that usually possess an Nterminal secretion signal peptide followed by a semi-conserved domain named the necrosis-inducing Phytophthora protein 1 (NPP1) domain (Gijzen and Nurnberger 2006). The original NLP isolated from Fusarium oxysporum corresponds to a 24$\mathrm{kDa}$ protein that induces cell death and ethylene accumulation in coca plants, and it was named the necrosis- and ethylene-inducing peptide 1 (Nep1) (Bailey 1995). Since then, many other NLP from plant-pathogenic bacteria, oomycetes, and fungi have been experimentally identified (Gijzen and Nurnberger 2006; Pemberton and Salmond 2004). With the increasing availability of microbial, fungal, and oomycete genome sequences, it has become apparent that NLP are widely distributed in pathogenic and nonpathogenic organisms (Gijzen and Nurnberger 2006; Oliva et al. 2010). This has led to a growing interest in determining the function of NLP and their roles in plantpathogen interactions. Most identified NLP not only trigger cell death but also elicit strong immune responses in dicotyle- 
donous plants (Qutob et al. 2006). Nonetheless, recent evidence from NLP crystal structure analysis and mutagenesis suggests that NLP can function as cytolytic toxins that damage cell membranes (Ottmann et al. 2009).

There is good evidence that the phytotoxicity of NLP can contribute to pathogen virulence. Expression of $F$. oxysporum Nep1 in Colletotrichum coccodes increases the virulence and the spectrum of hosts that can be infected (Amsellem et al. 2002). Mutants of Erwinia carotovora that are NLP-deficient reduce the virulence on host plants, and this effect is reversed by complementation (Mattinen et al. 2004; Pemberton et al. 2005). However, the complete deletion of NLP in fungal pathogens $M y$ cosphaerella graminicola and Botrytis elliptica did not yield any detectable reduction in virulence, suggesting that NLP are not virulence determinants in these interactions (Motteram et al. 2009; Staats et al. 2007a). Overall, it is likely that NLP from different pathogens play distinct roles and will require further exploration to determine their true functions. Likewise, the huge NLP gene families revealed by genome sequencing of $P$. sojae, $P$. infestans, and $P$. ramorum provide the genetic space for functional diversification through the process of relaxed selection.

Studies of NLP from Phytophthora spp. have focused on relatively few proteins. The $P$. sojae necrosis-inducing protein (PsojNIP, hereafter referred to as PsNLP1) is an NLP that was identified by expression analysis of putative secreted $P$. sojae cDNA in Nicotiana benthamiana using an Agrobacterium tumefaciens binary Potato virus X (PVX) vector (Qutob et al. 2002). Heterologous expression of full-length PsNLP1 can trigger cell death on soybean (Glycine max), Arabidopsis, and $N$. benthamiana; however, expression of PsNLP1 without the signal peptide does not cause cell death. This suggests that NLP require delivery to and recognition at the extra cytoplasmic side of the plant cell in order to trigger cell death (Qutob et al. 2002, 2006). An NLP from $P$. parasitica, NPP1, induces a rapid plant response on parsley including production of reactive oxygen species and mitogen-activated protein kinase activation (Fellbrich et al. 2002). A microarray analysis of gene expression in Arabidopsis leaves treated with NPP1 demonstrated that it triggers defense and immune responses similar to the bacterial pathogen-associated molecular pattern flagellin peptide (flg22) (Qutob et al. 2006). Three P. infestans cDNAs encoding putative secreted proteins similar to PsNLP1 and NPP1 were identified and named PiNPP1.1, PiNPP1.2, and PiNPP1.3 (Kanneganti et al. 2006). Transient expression using PVX showed that PiNPP1.1 but not PiNPP1.2 or PiNPP1.3 could trigger cell death in $N$. benthamiana and potato. It is known that PSNLP1 and PiNPP1.1 are specifically expressed at the late stages of infection, suggesting that NLP might facilitate the colonization of host tissues during the necrotrophic phase (Kanneganti et al. 2006; Qutob et al. 2002). However, it is also evident that predicted NLP genes from $P$. infestans and $P$. megakarya are expressed during zoospore, mycelium, and early biotrophic infection phase (Bae et al. 2005; Haas et al. 2009). Certainly it seems that the various Phytophthora NLP studies thus far represent only a beginning in the characterization of this large and diverse gene family.

The expansion of NLP gene families in Phytophthora spp. has been noted in whole-genome analyses (Haas et al. 2009; Tyler et al. 2006). The size of the NLP family in $P$. infestans $(n=$ $27)$, $P$. sojae $(n=39)$, and $P$. ramorum $(n=59)$ has been estimated through annotation but determining the exact number of functional or "real" genes encoding NLP is difficult because of the presence of numerous pseudogenes. Likewise, although it is clear that NLP can contribute to virulence as toxins, it is apparent that many members of this family do not possess toxic activity (Ottmann et al. 2009). In this article, we provide an analysis of the NLP gene family in P. sojae. Our objectives were to define a set of functional NLP genes, determine the prevalence of cell-death-inducing activity within the family by leaf infiltration assays, and identify any NLP genes subject to diversifying selective pressure through comparative sequence analysis.

\section{RESULTS}

In total, 33 real and 37 pseudogenes compose the $P$. sojae NLP gene family.

The sequences of PsNLP1 (Qutob et al. 2002) and PiNPP1.1 (Kanneganti et al. 2006) were used to search the $P$. sojae genome using the TBLASTN program and an expect (E) value cut-off $<10^{-15}$. In total, 70 predicted gene models were retrieved under these conditions (Fig. 1; Supplementary Table S1). We named these gene models sequentially, from PsNLP1 (PsojNIP) to $P S N L P 70$. All of the proteins encoded by these models have an NPP1 domain (PFAM: IPR008701) match with an E value < $10^{-16}$.

Previous reports suggested that many predicted NLP genes in Phytophthora spp. are pseudogenes (Gijzen and Nurnberger 2006; Haas et al. 2009; Tyler et al. 2006). The only P. sojae NLP gene studied in depth thus far is $P S N L P 1$. We carefully examined the remaining 69 predicted NLP gene models to distinguish real genes or pseudogenes. Matches of expressed sequence tags (EST) to the PsNLP11 (EST psMA007xI18f) and PsNLP55 (EST psMA007xI19f) genes suggest that they are real genes. In total, 30 PsNLP are predicted to have introns and, in at least 14 of these (PsNLP6, PsNLP12, PsNLP13, PsNLP15, PsNLP20, PsNLP26, PsNLP31, PsNLP35, PsNLP43, PsNLP47, PsNLP48, PsNLP61, PsNLP63, and $P s N L P 66)$, the intron placement provides a bypass to in-frame stop codons. Four NLP (PsNLP4, PsNLP53, PsNLP64, and PsNLP65) do not have intact NPP1 domains and their predicted protein sizes (100 to 140 amino acids) are remarkably shorter than previous identified NLP. Three NLP (PsNLP22, PsNLP28, and PsNLP62) are predicted to have unusually large

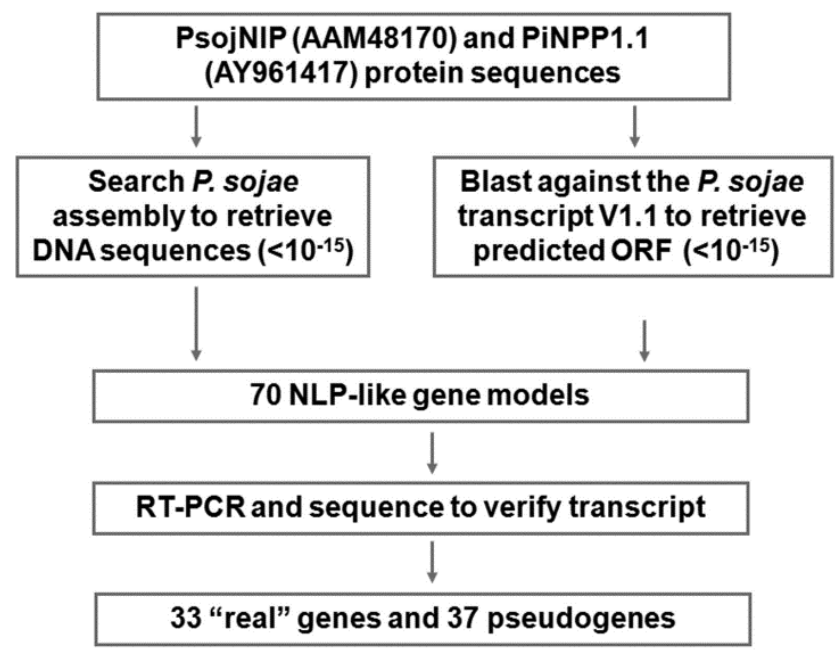

Fig. 1. Overview of the process to define the necrosis- and ethylene-inducing-like protein (NLP) family members in Phytophthora sojae. PsNLP1 (PsojNIP) and necrosis-inducing Phytophthora protein (NPP) PiNPP1.1 protein sequences were obtained from GenBank and used to search the $P$. sojae genome sequence assembly database V1.0 and $P$. sojae predicted transcript database V1.1. This analysis returned 70 NLP gene models. Available data from expressed sequence tag and microarray studies was integrated with results from reverse-transcriptase polymerase chain reaction (RT-PCR) analysis to test the gene models. ORF $=$ open reading frame. Overall, we delineated the 70 NLP gene models into 33 real genes and 37 pseudogenes. 
introns $(>1 \mathrm{~kb})$. To test the gene models for NLP with predicted introns, we performed reverse-transcriptase polymerase chain reaction (RT-PCR) analysis and sequenced resulting amplification products. Eight NLP (PsNLP2, PsNLP18, PsNLP33, PsNLP34, PsNLP36, PsNLP45, PsNLP49, and PsNLP52) generate clear RT-PCR products and possess unspliced predicted intron sequences within the transcript, producing frame-shifts in their predicted open reading frame (ORF). The PSNLP50 encodes a predicted protein with two tandem NPP1 domain repeats fused to a lipocalin-like domain; however, no transcript could be detected. Overall, for the 30 NLP with predicted introns, we found either that the predicted introns are not spliced from the transcripts or that no transcripts are detectable. We conclude that the introns are artifacts from the gene annotation program and that the 30 NLP represent pseudogenes.

We also examined the 40 NLP genes without predicted introns, and determined that seven of these are apparently pseudogenes. The PsNLP16, PsNLP67, PsNLP68, PsNLP69, and PsNLP70 genes encode only a fragment of the NPP1 conserved domain and overall lengths of the predicted proteins are unusually short. The $P s N L P 17$ sequence appears to be disrupted by a 6-kb fragment insertion, while PsNLP56 has a premature stop codon in the predicted coding region. Thus, our analysis of the NLP gene family in $P$. sojae separated the 70 potential NLP genes into two groups of 33 real genes and 37 pseudogenes, respectively.

The nucleotide sequences of the 33 NLP genes were aligned and used to construct a neighbor-joining phylogenetic tree, which delineated six NLP groups (Fig. 2A). Experiments and analysis were made based on the six NLP groups.

\section{Most $P$. sojae NLP are lacking key residues necessary for toxic activity.}

The PsNLP1, NPP1, and PiNPP1.1 pre-proteins derived from various Phytophthora spp. have clear secretory signal peptides (Fellbrich et al. 2002; Kanneganti et al. 2006; Qutob et al. 2002). Furthermore, transient expression of PsNLP1 in plant cells indicates that secretory signal peptide is required for celldeath activity (Qutob et al. 2006), and NLP are considered to be secreted toxins and extracellular effectors that function in the plant apoplast (Kamoun 2006).

Therefore, we determined whether the protein sequences of the 33 real NLP genes possessed secretory leader peptides using the SignalPv3.0 server (Bendtsen et al. 2004). The SignalP hidden Markov model (HMM) probabilities from 31 of the NLP were higher than 0.95 (Table 1). The SignalP HMM probability values of PsNLP14 and PsNLP40 were 0.817 and 0.864 , respectively. For SignalP NN mean S score, all the NLP had a value higher than 0.70, except PsNLP40 (0.541).

The protein length of the 33 NLP was 228 to 385 amino acids (Table 1). The $P s N L P 1$ gene encodes a 238-amino-acid protein which is similar in size to most of the $P$. sojae NLP family members. Analysis of the coding sequences using the conserved domain database server at the National Center for Biotechnology Information (NCBI) showed that the NPP1 domain E values were $10^{-42}$ to $10^{-79}$, with PsNLP1 returning an E value of $10^{-77}$. In addition to the signal peptide and NPP1 domain, previous reports showed that certain Phytophthora NLP have glutamine (Gln)- and proline (Pro)-rich hydrophilic domains (Gijzen and Nurnberger 2006) and Jacalin-like lectin domains (Bae et al. 2005). We determined that at least eight of 33 real NLP have additional domains. Thus, PsNLP10, PsNLP11, PsNLP38, PsNLP58, PsNLP59, and PsNLP60 each have Gln- and Pro-rich domains occurring between the N-terminal secretory peptide and the NPP1 domain, whereas PsNLP37 has only a Gln-rich domain in this position and PsNLP40 has a Gln-rich domain on its C-terminal (Table 1; Fig. 2B). We did not find any other domains or domain arrangements among the 33 NLP.

The NLP from groups 4,5 , and 6 are simple NLP, in that they do not possess any obvious additional sequence motifs

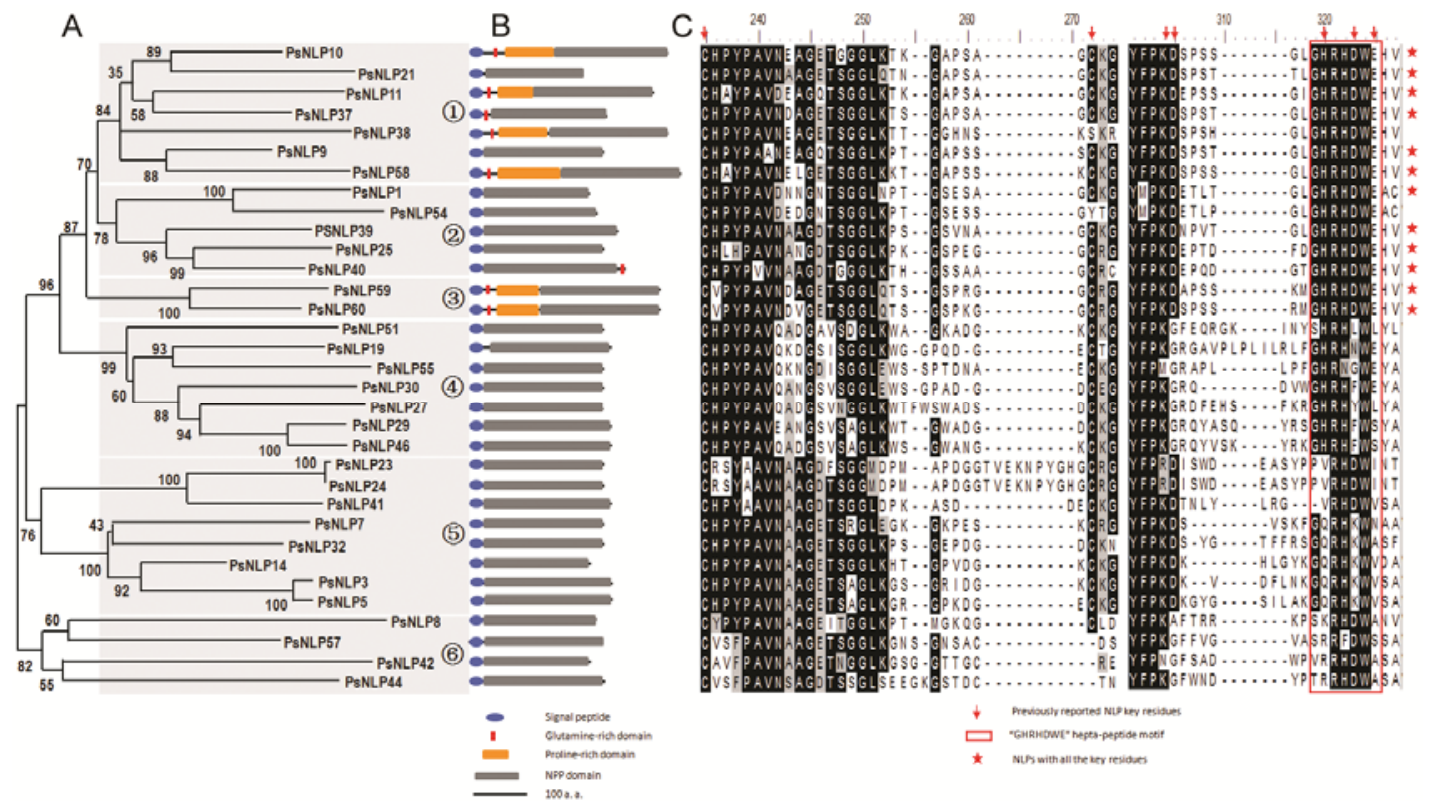

Fig. 2. Necrosis- and ethylene-inducing-like protein (NLP) genes in Phytophthora sojae display diversity in sequence. A, A neighbor-joining tree was constructed based on the nucleotide sequences of 33 real NLP genes by using MEGA4. Numbers at nodes represent the percentage of their occurrence in 10,000 bootstrap replicates and the scale bar shows the number of amino acid differences per site. Six groups of $P$. sojae NLP genes resulted from this phylogenetic analysis. B, Schematic view of 33 predicted NLP proteins (the present order matches the sequence alignment order in A). Protein domains or motifs are indicated in color, as follows: blue, predicted signal peptide; orange, proline-rich domain; red, glutamine-rich domain; and gray, necrosis-inducing Phytophthora protein (NPP) domain. The bar represents the length of 100 amino acids (a.a.). C, Protein sequence alignment of NLP (Bioedit V2005). Two conserved regions (230 to 270and 300 to 330 a.a.) are shown. Red arrows indicate conserved cysteines and key functional residues previously described (Ottmann et al. 2009). The Gly-His-Arg-His-Asp-Trp-Glu (GHRHDWE) heptapeptide motif is highlighted with a red box. Red stars indicate the PsNLP that contain all of the key residues for necrosis-inducing activity. 
besides the secretory peptides and the NPP1 domains. The two members of group 3, PsNLP59 and PsNLP60, each have a Gln- and Pro-rich domain. In group 1, four NLP have Gln- and Pro-rich domains and one NLP has a Gln-rich domain in the C terminal. Thus, the NLP with additional domains are not monophyletic but, nonetheless, all are restricted to the branch of the phylogenetic tree that includes groups 1, 2, and 3 (Fig. 2B).

The key residues for necrosis-inducing activity of $P$. parasitica NPP1 have been characterized by site-directed mutagenesis (Fellbrich et al. 2002; Ottmann et al. 2009). In order to examine whether these residues are conserved among $P$. sojae NLP, we conducted protein sequence alignment and compared amino acid sequences at the key sites (Fig. 2C). The data show that most of the PsNLP have two conserved cysteine (Cys) residues, which define these proteins as type I NLP (Fellbrich et al. 2002; Gijzen and Nurnberger 2006). The first Cys residue is conserved in all the NLP but the second Cys residue is missing in two PsNLP (NLP38 and NLP54). We also noted that particular NLP may contain additional Cys residues at nonconserved positions, such as the Cys residue occurring in PsNLP1 and PsNLP54 that is positioned immediately downstream from the Gly-His-ArgHis-Asp-Trp-Glu (GHRHDWE) heptapeptide motif. The central conserved GHRHDWE motif is present in NLP from groups 1 to 3; however, this motif has changed in sequence in NLP from groups 4 to 6 . The Arg and Trp residues in this motif are the only two residues that remained conserved in all 33 NLP but they are not important residues for necrosis-inducing activity based on our current knowledge. In addition to the pair of conserved Cys residues, the key residues for necrosis-inducing activity of Pythium aphanidermatum PyaNLP include three amino acids within the GHRHDWE motif $(318 \mathrm{H}, 321 \mathrm{D}$, and $323 \mathrm{E})$ and two residues upstream from this (302K and 303D) (Ottmann et al. 2009). These key residues are mostly conserved in the NLP from groups 1 to 3 but not in the NLP from groups 4 to 6 (Fig. 2C). Altogether, only 12 of 33 (36\%) of the NLP possess a full complement of these amino acids that are thought to be crucial for toxic activity.

\section{Only eight PsNLP are confirmed}

to cause necrosis by transient expression assay.

To determine the necrosis-inducing activity of the PsNLP, we selected genes for transient expression by agroinfiltration in $N$. benthamiana (Fig. 3). All 14 NLP from groups 1 to 3 were chosen along with four representative NLP (PsNLP7, PsNLP27, PsNLP51, and PsNLP44) from groups 4 to 6. The criteria we used to select representative NLP was based on a consideration of the signal peptide confidence, NPP domain E value, and reliable bootstrap value in the phylogenetic tree. All of the tested PsNLP were cloned into vector pGR107 with or without a hemagglutinin (HA) tag (C-terminal fusion pattern). In our experiments, PSNLP with or without HA tag do not show any difference in necrosis activity on $N$. benthamiana. The total protein of agroinfiltrated leaves expressing PsNLP with HA tag was isolated for Western blot analysis. Western blots show that all of the PsNLP are expressed in N. benthamiana (Supplementary Fig. S1). Surprisingly, only seven of the NLP caused a strong necrotic response when tested this way. In all, one additional NLP was weakly active whereas the remaining 11 NLP that were

Table 1. Summary of 33 necrosis- and ethylene-inducing-like protein (NLP) genes in the genome of Phytophthora sojae

\begin{tabular}{|c|c|c|c|c|c|c|c|}
\hline Gene name & Genome position ${ }^{a}$ & $\begin{array}{l}\text { Protein } \\
\text { length }\end{array}$ & $\begin{array}{c}\text { SignalP HMM } \\
\text { probability }^{\text {b }}\end{array}$ & $\begin{array}{l}\text { SignalP NN } \\
\text { mean } \mathbf{S} \text { score }\end{array}$ & $\begin{array}{l}\text { SignalP } \\
\text { length }^{b}\end{array}$ & $\begin{array}{l}\text { NPP1 domain } \\
\text { E value }\end{array}$ & Note $^{d}$ \\
\hline PsNLP1 & scaffold_72:377474-376582 & 238 & 0.998 & 0.862 & 19 & $1 \mathrm{E}-77$ & PsojNIP (Qutob et al. 2002) \\
\hline$P s N L P 3$ & scaffold_69:379951-380857 & 258 & 0.999 & 0.898 & 21 & $5 \mathrm{E}-54$ & $\ldots$ \\
\hline PsNLP5 & scaffold_69:327909-328825 & 261 & 0.999 & 0.898 & 21 & $2 \mathrm{E}-52$ & $\ldots$ \\
\hline PsNLP7 & scaffold_143:37102-38026 & 255 & 0.991 & 0.86 & 23 & $2 \mathrm{E}-51$ & $\ldots$ \\
\hline PsNLP8 & scaffold_148:25389-24494 & 247 & 1.000 & 0.885 & 17 & $3 \mathrm{E}-44$ & $\ldots$ \\
\hline PsNLP9 & scaffold_19:467612-468482 & 240 & 0.998 & 0.751 & 22 & $2 \mathrm{E}-78$ & .. \\
\hline PsNLP10 & scaffold_99:127115-127796 & 385 & 1.000 & 0.713 & 19 & $4 \mathrm{E}-79$ & N-term Gln-Pro-rich domain \\
\hline PsNLP11 & scaffold_99:40347-41162 & 330 & 1.000 & 0.835 & 19 & $2 \mathrm{E}-73$ & N-term Gln-Pro-rich domain \\
\hline PsNLP19 & scaffold_1:1534753-1533851 & 252 & 1.000 & 0.862 & 19 & $3 \mathrm{E}-66$ & $\ldots$ \\
\hline PsNLP21 & scaffold_54:462171-463030 & 237 & 0.998 & 0.917 & 20 & $6 \mathrm{E}-60$ & $\ldots$ \\
\hline PsNLP23 & scaffold_101:265605-266565 & 265 & 1.000 & 0.921 & 19 & $6 \mathrm{E}-55$ & $\ldots$ \\
\hline PsNLP24 & scaffold_101:222811-223771 & 265 & 1.000 & 0.923 & 19 & $9 \mathrm{E}-56$ & $\ldots$ \\
\hline PsNLP25 & scaffold_5:355835-356711 & 242 & 0.996 & 0.897 & 20 & $2 \mathrm{E}-68$ & $\ldots$ \\
\hline PsNLP27 & scaffold_14:153632-152741 & 246 & 0.982 & 0.848 & 19 & $3 \mathrm{E}-59$ & $\ldots$ \\
\hline PsNLP29 & scaffold_14:159584-158758 & 228 & 0.998 & 0.806 & 19 & $4 \mathrm{E}-66$ & $\ldots$ \\
\hline PsNLP30 & scaffold_14:160929-161824 & 247 & 1.000 & 0.924 & 20 & $1 \mathrm{E}-62$ & $\ldots$ \\
\hline PsNLP32 & scaffold_23:263208-262284 & 255 & 0.998 & 0.764 & 19 & $9 \mathrm{E}-60$ & $\ldots$ \\
\hline PsNLP38 & scaffold_3:367902-366669 & 340 & 1.000 & 0.752 & 19 & $1 \mathrm{E}-72$ & N-term Gln-Pro-rich domain \\
\hline PsNLP37 & scaffold_72:388074-388976 & 249 & 1.000 & 0.759 & 19 & $9 \mathrm{E}-75$ & T-term Gln-rich domain \\
\hline PsNLP39 & scaffold_72:389851-388986 & 239 & 0.987 & 0.718 & 19 & $4 \mathrm{E}-73$ & $\ldots$ \\
\hline PsNLP4O & scaffold_72:393098-392160 & 259 & 0.864 & 0.541 & 19 & $1 \mathrm{E}-68$ & C-term Gln-rich domain \\
\hline PsNLP41 & scaffold_84:24889-25787 & 248 & 1.000 & 0.874 & 19 & $3 \mathrm{E}-52$ & $\ldots$ \\
\hline PsNLP42 & scaffold_78:352325-353209 & 244 & 0.999 & 0.936 & 18 & $8 \mathrm{E}-42$ & $\ldots$ \\
\hline PsNLP44 & scaffold_191:55599-54683 & 253 & 1.000 & 0.952 & 19 & $2 \mathrm{E}-50$ & $\ldots$ \\
\hline PsNLP46 & scaffold_14:193433-194339 & 250 & 0.995 & 0.811 & 19 & $1 \mathrm{E}-66$ & $\ldots$ \\
\hline PsNLP51 & scaffold_14:235819-236725 & 250 & 1.000 & 0.859 & 19 & $1 \mathrm{E}-61$ & $\ldots$ \\
\hline PsNLP54 & scaffold_72:370763-371617 & 236 & 0.979 & 0.865 & 19 & $4 \mathrm{E}-68$ & $\ldots$ \\
\hline PsNLP55 & scaffold_8:1028311-1027413 & 248 & 1.000 & 0.882 & 19 & $6 \mathrm{E}-54$ & $\ldots$ \\
\hline PsNLP57 & scaffold_100:139153-140018 & 239 & 0.998 & 0.85 & 19 & $6 \mathrm{E}-56$ & $\ldots$ \\
\hline PsNLP58 & scaffold_55:218188-219555 & 377 & 0.999 & 0.859 & 19 & $2 \mathrm{E}-77$ & N-term Gln-Pro-rich domain \\
\hline PsNLP59 & scaffold_67:153614-152403 & 334 & 0.999 & 0.783 & 21 & $6 \mathrm{E}-69$ & N-term Gln-Pro-rich domain \\
\hline PsNLP60 & scaffold_67:166097-167330 & 340 & 1.000 & 0.917 & 17 & $3 \mathrm{E}-79$ & N-term Gln-Pro-rich domain \\
\hline
\end{tabular}

${ }^{a}$ Genome position refers to the NLP genes position in the $P$. sojae genome sequence assembly database V1.0.

${ }^{\mathrm{b}}$ Hidden Markov model (HMM) probability, NN mean S score, and signal peptide length are predicted using SignalPv3.0.

${ }^{c}$ Necrosis-inducing Phytophthora protein (NPP) domain blast E values were obtained from the National Center for Biotechnology Information conserved domain database.

${ }^{\mathrm{d}}$ Glutamine- and proline-rich domains were scanned by Motif Scan and shown in Gln- and Pro-. C/T-term refers to the position of the domain are in the C terminal or N terminal of the NLP protein sequence. 
tested did not produce any response. Five NLP (PsNLP1, PsNLP9, PsNLP37, PsNLP58, and PsNLP60) caused a strong necrosis phenotype by 6 days postinfection (dpi), whereas strong necrosis induced by PsNLP10 and PsNLP59 was not apparent until 7 dpi. Expression of PsNLP54 caused only weak necrosis-inducing activity. None of the PsNLP from groups 4 to 6 triggered cell death in our assay (Supplementary Fig. S2).
Our results show that certain NLP with Gln- and Pro-rich domains (PsNLP58, PsNLP59, PsNLP60, and PsNLP10) retain necrosis-inducing activity but others (PsNLP11 and PsNLP38) do not. We also noted that NLP lacking key residues are usually inactive in causing necrosis but possession of all the residues does not ensure activity. For example, PsNLP11 has key residues intact but does not cause necrosis. To determine whether

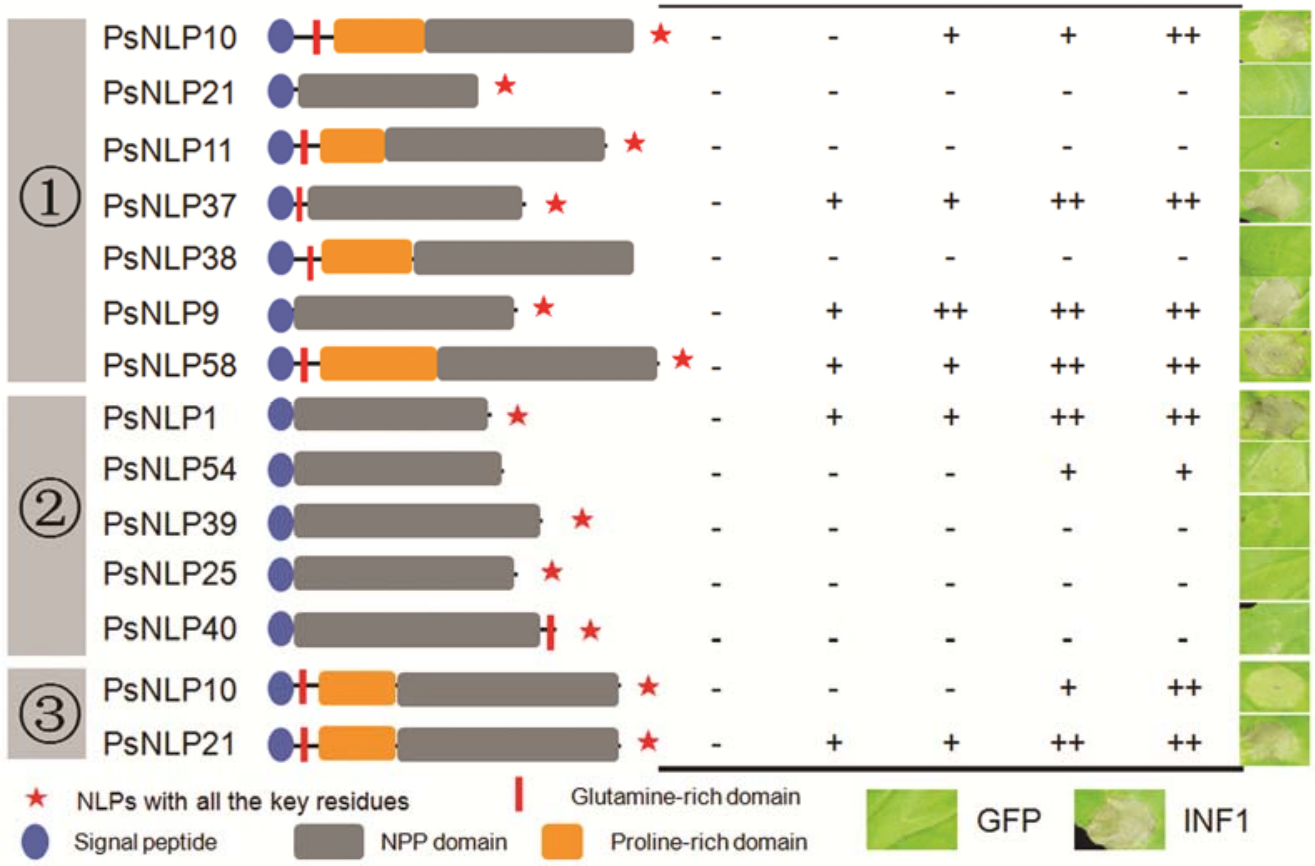

Fig. 3. PsNLP from groups 1 to 3 are tested for their necrosis-inducing activity on Nicotiana benthamiana by using Agrobacterium transient expression system. Left panel shows the protein structure scheme of 14 necrosis- and ethylene-inducing-like protein (NLP) genes with an intact heptapeptide motif. Protein domains or motifs are indicated in color, as follows: blue, predicted signal peptide; orange, proline-rich domain; red, glutamine-rich domain; and gray, necrosis-inducing Phytophthora protein (NPP) domain. Red stars indicated the PsNLP that contain all of the key residues for necrosis-inducing activity. Right panel shows the necrosis-inducing activity of these NLP. The necrosis-inducing activity is scored as follows: -, no necrosis; +, weak necrosis; and ++, strong necrosis. Number of days postinfiltration (dpi) with Agrobacterium spp. is indicated. Photos were from 7dpi. Results from expression of a negative control of green fluorescent protein (GFP) and positive control of $P$. infestans elicitin (INF1) are also shown for comparison. All of the experiments were repeated eight or more times.

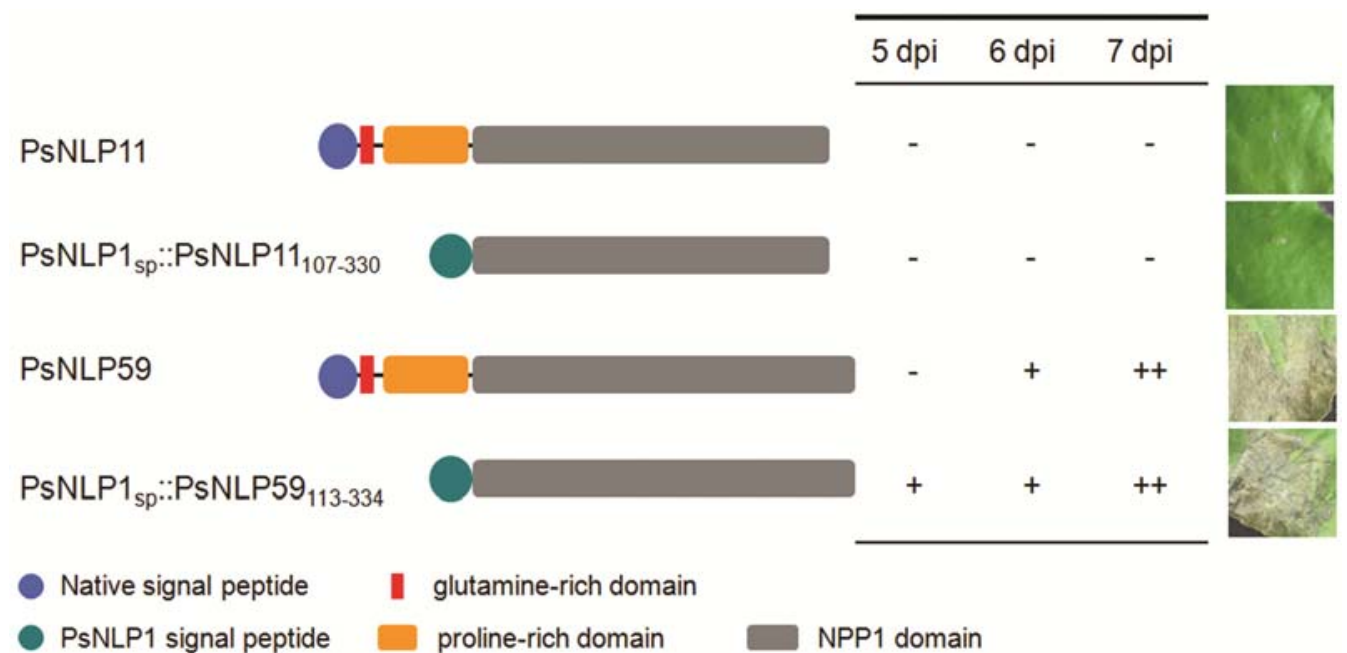

Fig. 4. Presence of glutamine-rich and proline-rich domains does not influence necrosis-inducing activity. The necrosis-inducing activity of native and chimeric proteins is illustrated. Blue ellipses indicate predicted native signal peptides, and green ellipses indicate necrosis- and ethylene-inducing-like protein (PsNLP1) signal peptide. Orange, red, and gray boxes represent the proline-rich domain, glutamine-rich domain, and necrosis-inducing Phytophthora protein 1 (NPP1) domain, respectively. Photos on the right show the necrosis-inducing activity of native and chimeric NLP. The necrosis-inducing activity is scored as follows: -, no necrosis; +, weak necrosis; ++, strong necrosis. Number of days postinfiltration (dpi) with Agrobacterium spp. is indicated. Photos were from $7 \mathrm{dpi}$. All of the infiltration experiments were repeated eight times. Each replicates contains four infiltration sites from two plant leaves. 
this may be caused by interference due to the Gln- and Prorich domain within PsNLP11, we created a chimeric protein, PsNLP1 $1_{\text {sp }}:$ PsNLP1 $11_{107-330}$, consisting of the secretory leader peptide of PsNLP1 fused to the NPP1 domain (amino acids 107 to 330) from PsNLP11. The chimeric protein cannot trigger cell death, indicating that the NPP1 domain of PsNLP11 is inactive (Fig. 4). Using a similar strategy, we removed the Gln- and Prorich domains from PsNLP59 to determine whether these domains were necessary for the necrosis-inducing activity of this protein. Results show that PsNLP59 and PsNLP $1_{\text {sp }}:$ PsNLP59 113 334 can trigger cell death with similar activity (Fig. 4). Thus, in these two instances (PsNLP11 and PsNLP59), the presence of Gln- and Pro-rich domains does not significantly influence necrosis-inducing activity either negatively or positively.

\section{Most NLP are expressed during cyst germination and late infection stages.}

Transcriptional profiling of NLP in Phytophthora spp. has not been undertaken except for a few genes. The PsNLPl and PiNPP1.1 genes have been shown to be upregulated during the late infection, necrotrophic growth stages (Kanneganti et al. 2006; Qutob et al. 2002). We gathered data from previous digital gene express (DGE), EST, and microarray studies and per- formed new experiments by RT-PCR to determine the transcriptional pattern of PsNLP (Supplementary Table S2). Three NLP (PsNLP1, PsNLP11, and PsNLP55) have EST hits, corresponding to psHA011iE04r, psMA007xI18f, and psMA007xI19f, respectively. A comprehensive microarray data set for Phytophthora. sojae (NCBI Gene Expression Omnibus series GSE15100) includes RNA samples from $P$. sojae mycelium, zoospore, germinating cysts, 24-h postinoculation (hpi) soybean tissues, and 48-hpi soybean tissues (Dong et al. 2009). We examined Affymetrix probes for NLP and found that 21 of 33 real NLP have perfect probes. We used the MAS5 algorithm (Affymetrix) for normalization and to compare hybridization signals from perfect and mismatched probe sets to classify genes as detected (MAS5 flag call = present or marginal), or not detected (MAS5 flag call = absent). By this method, only nine of 21 NLP targets on the array could be detected. Among the 12 NLP lacking perfect probes on the Affymetrix microarray, two (PsNLP1 and PsNLP11) had EST hits, providing evidence for their expression. For the remaining 10 NLP without any expression data, we performed real-time RT-PCR to test for transcripts of these genes. In total, eight of ten of these NLP were detectable, indicating that the transcripts of these genes were present. To further verify the expression of PsNLP, we also examined
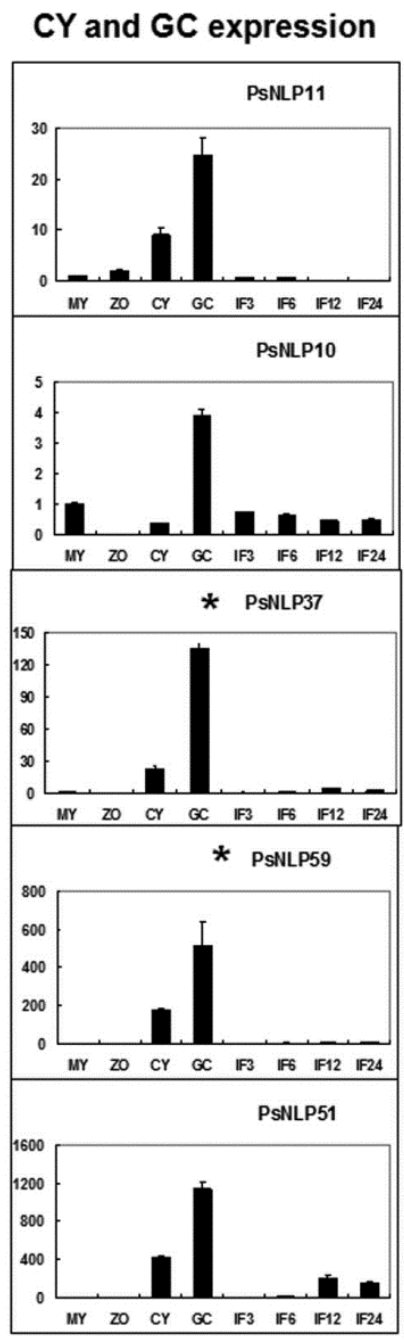

GC and IF expression

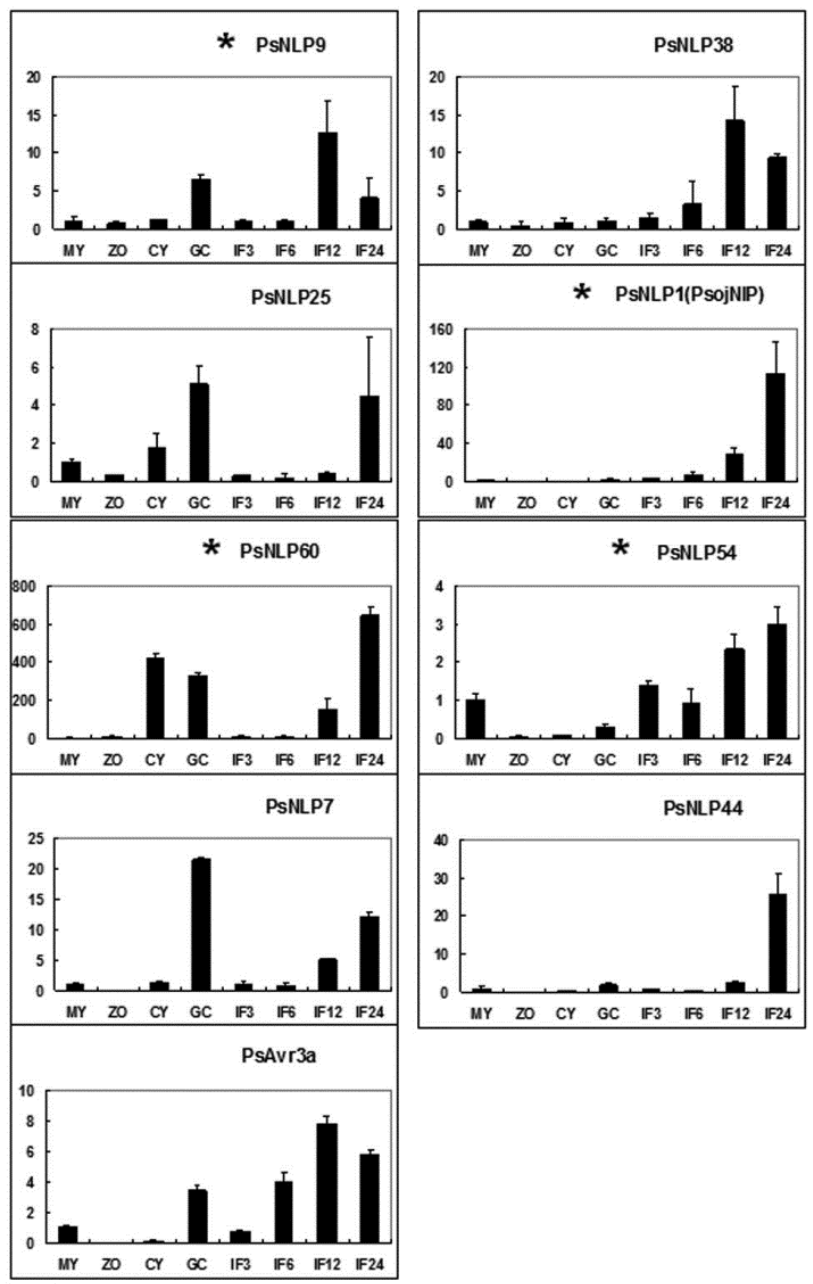

Fig. 5. Expression pattern of selected necrosis- and ethylene-inducing-like proteins (NLP) by real-time polymerase chain reaction. Shown are the expression patterns for 13 different NLP from Phytophthora sojae. The expression of the P. sojae Avr3a gene is also shown for comparison. Developmental or infection stages were as follows: MY, mycelium; ZO, zoospore; CY, cyst; GC, germinated cyst; IF3, infection site 3 h; IF6, infection site 6 h; IF12 infection site 12 h; and IF24, infection site $24 \mathrm{~h}$. For each NLP, the mycelium expression level serves as a reference point (relative expression = 1.0) for normalization. Various genes are grouped according to their similarity in expression patterns. An asterisk (*) indicates that the gene is positive for triggering necrosis on Nicotiana benthamiana by the Agrobacterium transient expression assay. 
these genes in $P$. sojae RNA sequencing data which were generated by using the Illumina 3'-tag DGE method (Ye et al. 2011). In 33 predicted real PsNLP genes, only PsNLP32 cannot be detected because it does not contain the detectable 3 '-tag. For the remaining 32 NLP genes, 26 genes were expressed based on the data. Among the 32 DGE-detectable PsNLP, 13 genes were detectable only at germinating cyst stages, six PsNLP were induced during late infection stages (12 or $24 \mathrm{hpi}$ ), and seven PsNLP showed double expression peaks at both germinatingcyst and late-infection stages.

In order to confirm or determine the expression pattern of the 19 PsNLP that were selected for the necrosis activity assay, we performed a real-time RT-PCR analysis on this set of predicted genes. In total, eight different development and infection stages were sampled, including mycelium, zoospore, cyst, and germinating cyst, at 3, 6, 12, and 24 hpi. Expressions of PsNLP1 (Kelley et al. 2010; Qutob et al. 2002) and Avr3a (Qutob et al. 2009) were examined and considered as controls because the transcriptional patterns of these genes are known from previous studies. We used a cycle threshold $(\mathrm{Ct})$ cut-off value $(>28)$ as a detection limit. Three genes (PsNLP21, PsNLP39, and PsNLP40) did not produce $\mathrm{Ct}$ values below this limit for any stage sampled, and we classified these genes as not detected. The remaining 16 of 19 NLP were expressed in at least one or more developmental stage sampled, and results for 13 of these are shown in Figure 5. The transcription pattern of these 13 PsNLP can be classified into three major groups according to the stages of highest expression, as follows: germinating cyst (PsNLP10, PsNLP11, PsNLP37, PsNLP51, and PsNLP59), germinating cyst and infection site (PsNLP9, PsNLP25, PsNLP7, and PsNLP60), and infection site (PsNLP1, PsNLP38, PsNLP44, and PsNLP54). Three genes (PsNLP58, PsNLP14, and PsNLP27) were detectable but did not clearly fall into one of these three groups (data not shown).

\section{Many NLP structural genes occur in clusters in the $P$. sojae genome.}

Many Phytophthora effector genes such as those encoding elicitins, cutinases, CRN, and RxLRs tend to be clustered in the genome (Haas et al. 2009; Jiang et al. 2006a). We examined the NLP genomic distribution pattern to determine how often these genes occurred in clusters. Among all 70 predicted NLP (including pseudogenes), at least 36 NLP occurred in groups of two or more whereas 34 NLP appeared to be more randomly distributed around the genome as singletons. The 36 NLP occurring in clusters mapped to nine different genomic regions (Supplementary Table S3). The largest group (cluster 1) contained 11 NLP spanning an 88-kb region, while another region (cluster 2 ), with nine NLP, including PsNLP1, occurred within $21 \mathrm{~kb}$ (Fig. 6). Cluster 1 and cluster 2 each contained a mix of real genes and pseudogenes but the genes in cluster 2 were more tightly packed. The genes adjacent to the NLP clusters were also noteworthy. For example, a group of three elicitin genes were next to NLP in cluster 2 . The other clusters, containing two or three NLP genes, were not larger than $18 \mathrm{~kb}$, except cluster 4 and cluster 8, which were near $40 \mathrm{~kb}$ each. Cluster 9 (PsNLP41 and PsNLP66) was located in the scaffold_84, near to a PcVsv1 homolog, a secreted spore adhesion protein containing thrombospondin type 1 repeats (Robold and Hardham 2005), and to two genes coding cysteine-rich secreted proteins.

\section{Different groups of NLP are shaped by positive selection.}

Selection pressure tests based upon nucleotide substitution patterns are widely used for investigating gene evolution. Recent evidence showed that many Phytophthora effectors are shaped by positive selection (Liu et al. 2005; Win et al. 2007). Considering that more than a half of the 33 real NLP from $P$. sojae lack any detectable necrosis-inducing activity yet show evidence of high expression, we hypothesized that many PsNLP genes may have evolved new functions. To detect particular amino acid sites under positive (diversifying) selection in the PsNLP family, we used the maximum likelihood (ML) method and the computer program codeml from the PAML 4.2a package (Yang 2007).

We first obtained 10 PsNLP1 orthologous sequences from five species of Phytophthora ( $P$. capsici, P. parasitica, $P$. infestans, $P$. megakarya, and $P$. ramorum) in addition to the original sequence from $P$. sojae P6497. The likelihood ratio test (LRT) between the null model M7 ( $\beta$ distribution) and the alternative model M8 ( $\beta+\omega$ distribution) was conducted. The difference between model M7 and model M8 was not statistically significant, as indicated by the LRT: $2 \Delta \mathrm{L}=2 \times[-4054.27-(-4054.2)]=$ 0.02 , which is lower than the $\chi^{2}$ critical value $(9.21$ at $1 \%$ significance level, with degrees of freedom $=2$ ). Thus, model M8 does not fit the data significantly better than model M7, suggesting that the PsNLP1 orthologs are not under positive selection.

We then obtained additional sequences for the 33 real PsNLP from three other $P$. sojae strains (P7064, P7074, and P7076) (discussed below). Sequences for the RxLR Avr gene Avr3c alleles were also obtained for comparison (Dong et al. 2009). Each of the 33 real NLP genes from $P$. sojae P6497 is represented in each of the three additional genomes (P7064, P7074, and P7076), indicating that none of these genes has been deleted among this set of four strains. All of the 132 collected $P$. sojae NLP sequences aligned into six groups as predicted by the previous phylogenetic analysis on NLP from P6497 (Supplemen-
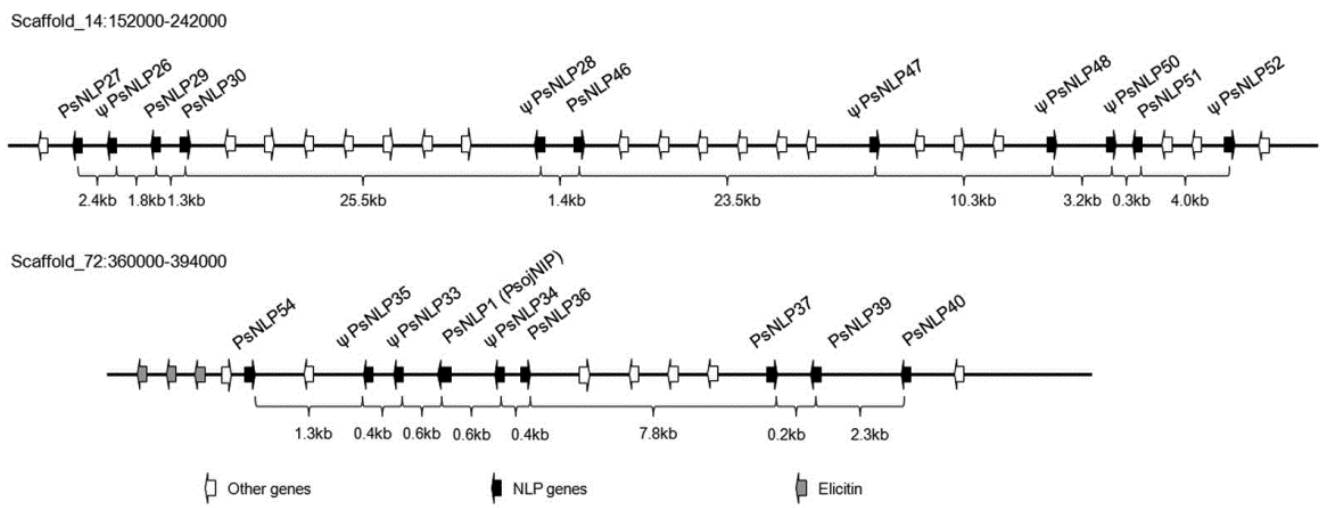

Fig. 6. Phytophthora sojae necrosis- and ethylene-inducing-like protein (NLP) genes are clustered in the genome. Two different genomic regions with a high density of NLP genes are shown. Predicted genes and direction of transcription are indicated as follows: black arrow, NLP gene; gray arrow, elicitin gene; white arrow, other predicted gene. The symbol Psi $(\Psi)$ shows predicted pseudogenes. Distances between predicted NLP genes are also shown, in kilobase pairs $(\mathrm{kb})$. 
tary Fig. S3). PsNLP used for positive selection test were confirmed as orthologs based on the phylogenetic tree. The LRT between model M7 and model M8 was performed to analyze selection in each of the groups. The difference between model M7 and model M8 was statistically significant in groups 1,5 , and 6, with the $2 \Delta \mathrm{L}$ values for these groups being $14.09,46.88$, and 9.95 , respectively. All of these values are greater than the $\chi^{2}$ critical value (Table 2), suggesting that these PsNLP are under positive selection. For groups 2, 3, and 4, the difference between model M7 and model M8 was not statistically significant, suggesting that they are under purifying selection.

The NLP from group 5 present a surprisingly high $2 \Delta \mathrm{L}$ value (46.88), even exceeding the $2 \Delta \mathrm{L}$ value (33.44) calculated for the Avr factor Avr3c. This data indicates that NLP from group 5 are rapidly evolving in $P$. sojae. The Empirical Bayes theorem was applied to identify seven amino acid sites $(55 \mathrm{D}$, 77S, 80I, 86G, 119F, 120L, and 169R from PsNLP3) implicated as being under positive selection, with $>95 \%$ confidence under model M8 in the group 5 PsNLP. Among these sites, three (80I, 119F, and 169R) are under positive selection, with $>99 \%$ confidence using model M8 (Table 2). All of these sites were located in the NPP1 domain but none of the sites corresponded to any of the previously identified key amino acid residues for necrosis-inducing activity (Supplementary Fig. S4).

Mapping of the seven sites under positive selection to the three-dimensional crystal structure of an NLP from Pythium aphanidermatum (Ottmann et al. 2009) indicated that most (55D, 77S, 80I, 119F, and 120L) were clustered to one side of the protein face, adjacent to the negatively charged binding cav- ity that forms around the GHRHDWE heptapeptide motif (Fig. 7). With the exception of 196R, which is missing in Pythium NLP sequence and, thus, cannot be mapped, all of the positive selection sites were predicted to be exposed on NLP surface.

\section{DISCUSSION}

Since the first NLP was identified in culture filtrates of the vascular wilt fungus $F$. oxysporum (Bailey 1995), the proteins have been found or predicted to occur in a great variety of microbes, including fungi, oomycetes, and bacteria (Gijzen and Nurnberger 2006; Oliva et al. 2010). For fungal plant pathogens with NLP, the genes are usually present in the genome in one or a few copies. For instance, Sclerotinia sclerotiorum, $B$. elliptica, B. cinerea, and Moniliophthora perniciosa each have two known NLP genes (Dallal Bashi et al. 2010; Garcia et al. 2007; Schouten et al. 2008; Staats et al. 2007a), whereas the wheat pathogen Mycosphaerella graminicola has only one known NLP (Motteram et al. 2009; Wang et al. 2004). Some fungal pathogens have more NLP copies; for example, a recent release of the Verticillium dahliae genome sequence uncovered that approximately eight NLP are present in the genome (Broad Verticillium database). However, NLP have definitely undergone a large expansion in oomycete genomes (Gijzen and Nurnberger 2006). In our analysis, we found 70 potential NLP in the Phytophthora sojae genome and separated these into 33 real genes and 37 pseudogenes. This is consistent with past estimates that approximately half or more of the NLP predicted by gene annotation programs are pseudogenes (Gijzen

Table 2. Test for amino acid sites under positive selection in necrosis- and ethylene-inducing-like proteins (NLP) from Phytophthora sojae

\begin{tabular}{|c|c|c|c|c|c|c|c|c|c|c|}
\hline $\begin{array}{l}\text { NLP } \\
\text { group }\end{array}$ & $\begin{array}{c}\text { No. of } \\
\text { sequences }^{\mathrm{a}}\end{array}$ & Model $^{\mathbf{b}}$ & Estimate parameters & $\operatorname{InL}^{c}$ & $\begin{array}{c}\text { Sites under } \\
\text { positive selection }^{d}\end{array}$ & $\begin{array}{c}\text { Model } \\
\text { comparison }\end{array}$ & $2 \Delta \mathrm{L}^{\mathrm{e}}$ & 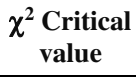 & FD ${ }^{f}$ & $P$ value \\
\hline Group 1 & 28 & $\begin{array}{l}\mathrm{M} 7(\beta) \\
\mathrm{M} 8(\beta+\omega>1)\end{array}$ & $\begin{aligned} \mathrm{p} & =0.35186, \mathrm{q}=1.93799 \\
\mathrm{p} 0 & =0.90580, \mathrm{p}=0.60483 \\
\mathrm{q} & =6.21696, \mathrm{p} 1=0.09420 \\
\mathrm{w} & =1.15772\end{aligned}$ & $\begin{array}{l}-3,300.04 \\
-3,293\end{array}$ & $\begin{array}{l}\text { Not allowed } \\
\text { None }\end{array}$ & M7 vs. M8 & 14.09 & 9.21 & 2 & $<0.01$ \\
\hline Group 2 & 20 & $\begin{array}{l}\operatorname{M} 7(\beta) \\
\operatorname{M} 8(\beta+\omega>1)\end{array}$ & $\begin{aligned} \mathrm{p} & =0.55916, \mathrm{q}=5.02723 \\
\mathrm{p} 0 & =0.96002, \mathrm{p}=0.68167 \\
\mathrm{q} & =7.33176, \mathrm{p} 1=0.03998 \\
\mathrm{w} & =2.43376\end{aligned}$ & $\begin{array}{l}-3,061.83 \\
-3,059.47\end{array}$ & $\begin{array}{l}\text { Not allowed } \\
\text { None }\end{array}$ & M7 vs. M8 & 4.73 & 9.21 & 2 & $\begin{array}{l}\cdots \\
\cdots\end{array}$ \\
\hline Group 3 & 8 & $\begin{array}{l}\mathrm{M} 7(\beta) \\
\mathrm{M} 8(\beta+\omega>1)\end{array}$ & $\begin{aligned} \mathrm{p} & =0.12901, \mathrm{q}=0.41247 \\
\mathrm{p} 0 & =0.89331, \mathrm{p}=0.38160 \\
\mathrm{q} & =2.71312, \mathrm{p} 1=0.10669 \\
\mathrm{w} & =10.19149\end{aligned}$ & $\begin{array}{l}-2,047.82 \\
-2,046.38\end{array}$ & $\begin{array}{l}\text { Not allowed } \\
\text { None }\end{array}$ & M7 vs. M8 & 2.88 & 9.21 & 2 & $\begin{array}{l}\cdots \\
\cdots\end{array}$ \\
\hline Group 4 & 28 & $\begin{array}{l}\operatorname{M} 7(\beta) \\
\operatorname{M} 8(\beta+\omega>1)\end{array}$ & $\begin{aligned} \mathrm{p} & =0.76429, \mathrm{q}=5.16234 \\
\mathrm{p} 0 & =0.99974, \mathrm{p}=0.76542 \\
\mathrm{q} & =5.17748, \mathrm{p} 1=0.00026 \\
\mathrm{w} & =2.64050\end{aligned}$ & $\begin{array}{l}-4,021.66 \\
-4,021.66\end{array}$ & $\begin{array}{l}\text { Not allowed } \\
\text { None }\end{array}$ & M7 vs. M8 & $\begin{array}{l}\ldots \\
0\end{array}$ & 9.21 & $\begin{array}{l}\cdots \\
2\end{array}$ & $\begin{array}{l}\cdots \\
\cdots\end{array}$ \\
\hline Group 5 & 32 & $\begin{array}{l}\mathrm{M} 7(\beta) \\
\mathrm{M} 8(\beta+\omega>1)\end{array}$ & $\begin{aligned} \mathrm{p} & =0.34243, \mathrm{q}=0.84540 \\
\mathrm{p} 0 & =0.93168, \mathrm{p}=0.43966 \\
\mathrm{q} & =1.40731, \mathrm{p} 1=0.06832 \\
\mathrm{w} & =12.60624\end{aligned}$ & $\begin{array}{l}-3,498.21 \\
-3,474.77\end{array}$ & $\begin{array}{l}\text { Not allowed } \\
\underline{55 \mathrm{D}} \underline{77 \mathrm{~S}} \mathbf{8 0 \mathrm { I }} \underline{86 \mathrm{G}} \\
\mathbf{1 1 9 F} \underline{\mathbf{1 2}} \underline{\mathbf{1 6 9 R}}\end{array}$ & $\begin{array}{c}\text {... } \\
\text { M7 vs. M8 }\end{array}$ & 46.88 & 9.21 & $\dddot{m}$ & $<0.01$ \\
\hline Group 6 & 16 & $\begin{array}{l}\mathrm{M} 7(\beta) \\
\mathrm{M} 8(\beta+\omega>1)\end{array}$ & $\begin{aligned} \mathrm{p} & =0.53094, \mathrm{q}=1.99824 \\
\mathrm{p} 0 & =0.81906, \mathrm{p}=0.87146 \\
\mathrm{q} & =6.44751, \mathrm{p} 1=0.18094 \\
\mathrm{w} & =2.11592\end{aligned}$ & $\begin{array}{l}-3,033.83 \\
-3,028.85\end{array}$ & $\begin{array}{l}\text { Not allowed } \\
\text { None }\end{array}$ & $\begin{array}{c}\ldots \\
\text { M7 vs. M8 }\end{array}$ & $\begin{array}{l}\ldots \\
9.95\end{array}$ & 9.21 & $\begin{array}{l}\ldots \\
2\end{array}$ & $<0.01$ \\
\hline Avr3c & 5 & $\begin{array}{l}\mathrm{M} 7(\beta) \\
\mathrm{M} 8(\beta+\omega>1)\end{array}$ & $\begin{aligned} \mathrm{p} & =1.55183, \mathrm{q}=0.00500 \\
\mathrm{p} 0 & =0.90074, \mathrm{p}=18.09903 \\
\mathrm{q} & =0.00500, \mathrm{p} 1=0.09926 \\
\mathrm{w} & =41.68231\end{aligned}$ & $\begin{array}{l}-1,079.68 \\
-1,062.96\end{array}$ & $\begin{array}{l}\text { Not allowed } \\
\text { 51E 95T } \\
\text { 133K 169Q 199I } \\
\text { 216R }\end{array}$ & $\begin{array}{c}\ldots \\
\text { M7 vs. M8 }\end{array}$ & $\begin{array}{c}\ldots \\
33.44\end{array}$ & 9.21 & $\begin{array}{l}\ldots \\
2\end{array}$ & $<0.01$ \\
\hline
\end{tabular}

\footnotetext{
${ }^{a}$ Six groups of NLP-like genes from four sequenced P. sojae strains (P6497, P7064, P7074, and P7076) are collected from VBI 454 P. sojae genome sequence database.

${ }^{\mathrm{b}}$ Likelihood ratio test for NLP-like genes and avirulent gene Avr3c (positive control) are performed by using PAML soft and calculated by using M7 and M8 model.

${ }^{\mathrm{c}}$ Log likelihood value.

${ }^{\mathrm{d}}$ Amino acid sites inferred to be under positive selection with a probability $>99 \%$ are in bold and $>95 \%$ are underlined.

${ }^{\mathrm{e}}$ Likelihood ratio test: $2 \Delta \mathrm{L}=2 \times\left(\mathrm{InL}_{\text {alternative hypothesis }}-\mathrm{InL}_{\text {null hypothesis }}\right)$.

${ }^{\mathrm{f}}$ Freedom degree $=2$.
} 
and Nurnberger 2006; Oliva et al. 2010). Also, previous estimates of real NLP genes in the $P$. sojae, $P$. infestans, and $P$. ramorum genomes ranged from 27 to 40 (Haas et al. 2009; Tyler et al. 2006). Recently, seven real NLP genes were proposed in the Pythium ultimum genome (Levesque et al. 2010) and 10 in Hyaloperonospora arabidopsidis genome (Baxter et al. 2010). Thus far, it is clear the Phytophthora spp. possess the largest NLP gene families and it is natural to assume that the proteins play an important role in their lifestyle.

We could not verify the presence of introns in any Phytophthora sojae NLP and we propose that introns in P. sojae NLP genes are an artifact caused by gene prediction programs. We assume that PsNLP do not contain introns, until proven otherwise. Known NLP genes typically encode proteins with a secretory signal peptide followed by an NPP1 domain. In our analysis, nearly all the real PsNLP possessed a signal peptide based on SignalP HMM probability test. Exceptions were PsNLP14 and PsNLP40, which returned probability scores $<0.95$. All the real PsNLP had an NPP1 domain match with an $E$ value $<10^{-42}$. A few reports have suggested that certain NLP can have additional motifs or domains that are different from typical NLP. Bae and associates (2005) identified PmegNEP7 (accession number AY741090) by sequencing a 525-bp 5' rapid amplification of cDNA ends product from $P$. megakarya. PmegNEP7 is predicted to have two partial domains consisting of a typical NPP1 domain and a Jacalin-like lectin domain. However, we did not find any predicted NLP (either real or pseudogene) of this kind in P. sojae.

A novel class of NLP with a Gln- and Pro-rich hydrophilic domain inserted between the signal peptide and NPP1 domain was discovered in $P$. sojae and $P$. ramorum genomes (Gijzen and Nurnberger 2006). Our genomic analysis of PsNLP indicates that there are a total of six NLP (PsNLP11, PsNLP10, PsNLP38, PsNLP58, PsNLP59, and PsNLP60) with additional Gln- and Pro-rich domains. The Gln-rich region is characterized by a cluster of seven to 14 Gln residues, whereas Pro-rich regions contain four to six tandem Thr-Pro-Ala-Pro repeats. These domains are usually located at the $\mathrm{N}$ terminal between the signal peptide and NPP1 domain, the exceptions being PsNLP40 with a Gln-rich domain at its C-terminal domain and PsNLP37 with a Gln-rich domain at its N-terminal (Fig. 2B).
In addition to their variable domain structure, NLP can also vary in their necrosis-inducing activity. For example, paralogous NLP BcNEP1 and BcNEP2 from the necrotrophic plantpathogenic fungus $B$. cinerea were compared and it was found that host plants are more sensitive to BcNEP1 than BcNEP2 (Schouten et al. 2008). Kanneganti and associates (2006) compared the necrosis-inducing activities among PiNPP1.1, PiNPP1.2 and PiNPP1.3 from P. infestans and reported that only PiNPP1.1 could strongly induce cell death. We tested 19 PsNLP for necrosis-inducing activity by transient expression in $N$. benthamiana and discovered that fewer than half ( 8 of 19) were active. We further classified these into strongly active (five of eight) and weakly active (three of eight) NLP. PsNLP1 (PsojNIP) is included among the five strongly active PsNLP for which the necrosis phenotype could be observed at 4 dpi. This rapid necrotic reaction is faster than necrosis induced by expression of the $P$. infestans elicitin INF1. The five strongly active NLP include predicted proteins with (PsNLP10, PsNLP58, and PsNLP60) and without (PsNLP1 and PsNLP9) additional Gln- and Pro-rich domains. Among the weakly active NLP, PsNLP54 is the weakest NLP with necrosis activity. Despite the fact that PsNLP54 is the closest paralog to PsNLP1, we did not expect it to display any activity because it is lacking a conserved Cys residue. Previous studies on $P$. parasitica NPP1 have shown that the two conserved Cys residues of type I NLP are essential for activity (Fellbrich et al. 2002). Each of these two Cys residues normally occurs in the vicinity of amino acids 55 to 68 and 82 to 96 , respectively. The PsNLP54 sequence contains the first conserved Cys residue (Cys56). The second Cys residue of PsNLP54 (Cys128) is far downstream from the conserved position but in the same place as the third Cys residue (Cys128) of PsNLP1. Perhaps Cys128 of PsNLP54 is able to partially compensate for the loss of Cys82; however, this remains to be tested. Considering all the results from the PsNLP activity tests, domain structure, and sequence analysis, we cannot point to any underlying patterns or characteristics that distinguish active from nonactive NLP.

Although we could not find a clear pattern to predict the necrosis-inducing activity of PsNLP, our results are mostly congruent with previous studies that identified key residues for NLP activity. In addition to the two conserved Cys residues, key resi-
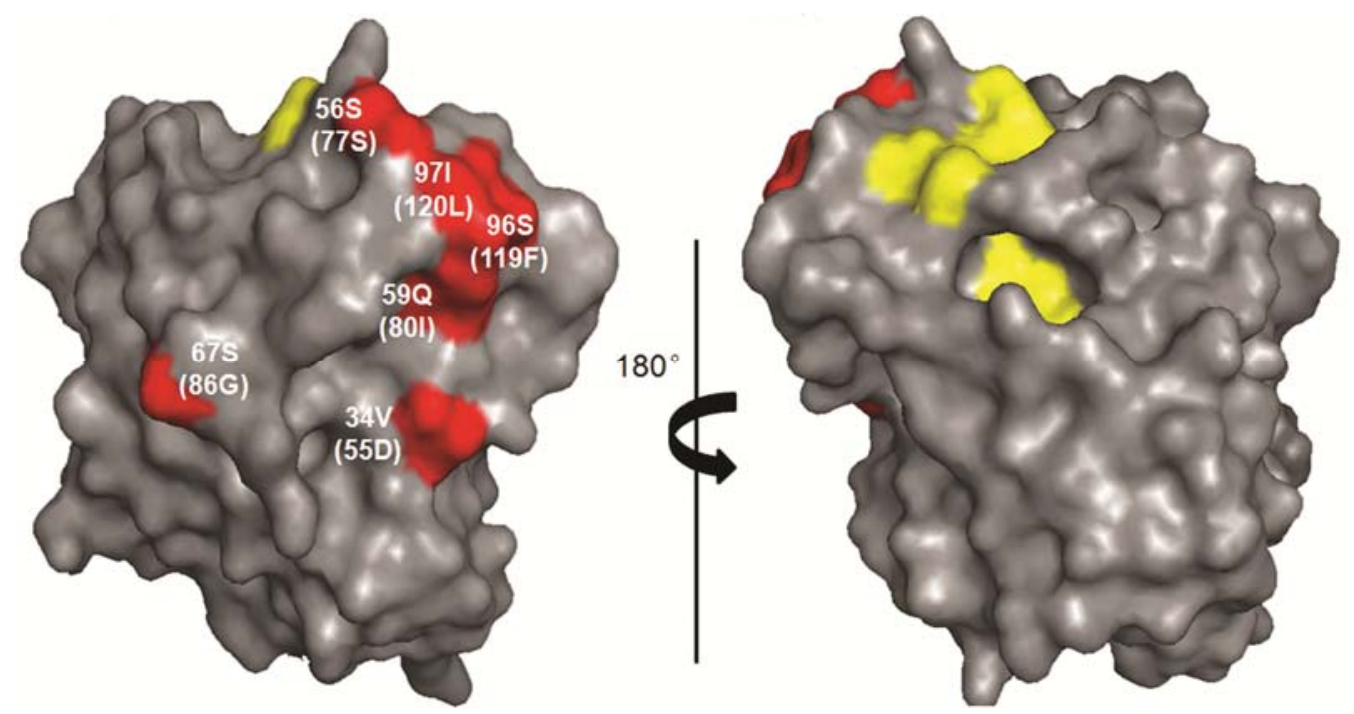

Fig. 7. Positive selection sites on the necrosis- and ethylene-inducing-like protein (NLP) surface. The NLP surface model is graphically illustrated by PyMOL using Pythium NLP (PDB ID: 3GNU) as a template. The NLP activity-related residues (92K, 93D, and Gly-His-Arg-His-Asp-Trp-Glu [GHRHDWE] motif) are highlighted in yellow. Residues that are predicted under positive selection in Phytophthora sojae NLP group 5 are marked in red. For each positive selection residue, the position and amino acid are shown for both the Pythium NLP template and P. sojae PsNLP3 (in brackets). One residue (196R in PsNLP3) missing in the Pythium NLP sequence is not shown in the NLP surface model. 
dues previously identified for $P$. parasitica NPP1 include H101, D104, and E106 in the GHRHDWE motif and K92 and D93 outside of the motif. These residues are crucial to phytotoxic activity and microbial virulence (Ottmann et al. 2009). With the exception of PsNLP54 which lacks a conserved Cys residue, the PsNLP that we found to be active possessed all of the key residues. Nonetheless, we found six PsNLP possessing all of the key residues that are not able to trigger necrosis. We also performed a sequence alignment of phytotoxic and nonphytotoxic NLP but failed to find any additional residues that might be important for necrosis-inducing activity. Remarkably, none of the PsNLP from groups 4 to 6 possessed all of the key conserved residues and, predictably, the NLP that we selected from these groups did not cause necrosis. Although the PsNLP from group 4 to 6 did not possess key residues required for necrosis, and did not cause necrosis, several were highly expressed during cyst germination and infection.

The expression pattern of selected NLP had been described in previous studies. It is known that PsNLP1 is significantly upregulated in planta at 48 hpi (Qutob et al. 2002), and that PiNPP1.1 is only detectable at late infection stages (4 dpi), whereas the transcripts of PiNPP1.2 and PiNPP1.3 accumulate as infection develops (Kanneganti et al. 2006). These studies indicated that NLP expression is associated with the transition from biotrophic to necrotrophic growth, and led to the hypothesis that NLP might contribute to host cell death as phytotoxins. However, more recent studies have shown that several $P$. infestans NLP genes are expressed during the early biotrophic phase of disease (Haas et al. 2009). We have now examined PSNLP expression patterns from microarray data and performed transcriptional profiling of 19 PsNLP by real-time RTPCR. Although we could not associate expression patterns with any structural features or phytotoxic activity of the predicted proteins, most PsNLP were highly expressed during cyst germination or late infection stages. It was not expected that phytotoxic NLP would be highly expressed during cyst germination in a hemibiotrophic pathogen such as $P$. sojae, because host cell death at this stage is counter-productive to establishing a successful infection. Possibly, the necrosis-inducing activity of certain NLP expressed at this stage is suppressed by other effectors delivered to the host by the pathogen. Alternatively, for NLP that do not possess necrosis-inducing activity, their high expression during cyst germination may provide clues for other functional roles for NLP; for instance, as adhesive or nutrient-releasing proteins, or hydrolytic enzymes.

Another important finding of the present work that supports the hypothesis of alternative functional roles for PsNLP is the result from the nucleotide substitution analysis among orthologous NLP from different $P$. sojae strains. Although most of the PsNLP are under purifying selection, the group 5 NLP appeared to be under strong positive selection. Moreover, the sites we identified as under positive selection were all different from previously reported key residues that are necessary for phytotoxic activity (Ottmann et al. 2009), and from the sites under positive selection identified in NLP from Botrytis spp. (Staats et al. 2007b). Pathogen effector proteins that are under positive selection are often considered to operate at the forefront in evolution in host-microbe interactions. For example, RxLR proteins and PcF toxins show clear signs of positive selection, whereas elicitins appear to be under purifying selection (Liu et al. 2005; Oh et al. 2009). Our finding that seven distinct residues of group 5 PsNLP displayed strong positive selection signals suggests an important role for these proteins in the host-pathogen interaction that potentially is distinct from the phytotoxic activity of other NLP.

The large size of the PsNLP gene family, the prevalence of pseudogenes, and the variation in $\mathrm{Ka} / \mathrm{Ks}$ ratios among the sub- family groups are characteristics that are common to proteins under diversifying selective pressures. Duplications that lead to expansion of a gene family cause redundancy and enable altered or new functional properties to arise, by processes called sub- and neo-functionalization. In the case of secreted effectors from Phytophthora spp., it is known that the corresponding genes are often clustered in the genome. Gene clusters of elicitins (Jiang et al. 2006b), cutinases (Jiang et al. 2005), CRN (Haas et al. 2009), and RxLR Avr factors (Dong et al. 2009; Qutob et al. 2009) have all been described. Past studies on NLP from $P$. sojae and P. megakarya have shown that paralogous NLP genes can occur in close proximity (Bae et al. 2005; Garcia et al. 2007; Qutob et al. 2002). We have now examined the entire PsNLP family and discovered two genomic regions that are particularly rich in NLP genes, including an 88-kb region containing 11 NLP (including six pseudogenes) located on Scaffold_14, and nine NLP (including PsojNIP and three pseudogenes) clustered in a $22-\mathrm{kb}$ region on Scaffold_72.

The expansion of the PsNLP family has led to loss of the conserved GHRHDWE motif in the subfamily groups 4 to 6 . We assume that the PsNLP from groups 1 to 3 are closer to the ancestral NLP because the GHRHDWE motif is mostly conserved in these proteins, and this motif is a characteristic of NLP from fungi prokaryotic organisms (Gijzen and Nurnberger 2006). The large number of group 4 to 6 PsNLP, the loss of the conserved GHRHDWE motif, and their apparent lack of phytotoxic activity suggest that these proteins have evolved to fill new functions. Recently, 27 NLP homologs were identified in the downy mildew pathogen $H$. arabidopsidis (Cabral et al. 2012). Half of the $H$. arabidopsidis NLP homologs are predicted to be pseudogenes. None of the $H$. arabidopsidis NLP could trigger cell death on tobacco or Arabidopsis, although some of the NLP contain all the amino acids that are required for necrosis-inducing activity. Most of the $H$. arabidopsidis $N L P$ showed a transcriptional peak at early infection stages. Thus, the NLP of $H$. arabidopsidis are similar to members of the $P$. sojae NLP family in many respects. Taken together, the results suggest that NLP have evolved new functions in biotrophic infection stages.

Overall, we believe that the organization, phylogenetic classification, and $\mathrm{Ka} / \mathrm{Ks}$ analysis of the PsNLP gene family and functional testing of a diverse array of representative genes have provided new insight into this important class of effectors. At a time when there seems to be a consensus emerging that NLP function as pore-forming phytotoxins, our results suggest that particular PsNLP subfamily groups have evolved alternative roles. This hypothesis will naturally require additional work to substantiate and further develop.

\section{MATERIALS AND METHODS}

\section{Plant and microbe cultivation.}

$N$. benthamiana plants were grown in Styrofoam cups containing disinfected soil and placed in a greenhouse at $25^{\circ} \mathrm{C}$ with a cycle of 16 and $8 \mathrm{~h}$ of light and darkness, respectively. For agroinfiltration, 5- to 6-week-old plants were used. $P$. sojae P6497, the genome-sequenced reference strain, was used in this study. The $P$. sojae cultures were routinely maintained on $2.5 \%$ vegetable (V8) juice medium at $25^{\circ} \mathrm{C}$ in the dark (Qutob et al. 2000). Samples of mycelium, zoospores, and encysted zoospores were prepared as previously described (Hua et al. 2008). Cysts were allowed to germinate at $25^{\circ} \mathrm{C}$ for $6 \mathrm{~h}$. Infection assays with $P$. sojae were performed by inoculation of soybean leaves with mycelium. For samples at 3 and $6 \mathrm{hpi}$, mycelium was selectively removed from the infection site; whereas, for samples at 12 and $24 \mathrm{hpi}$, the entire infection 
area, including soybean leaf tissue, was collected. All of the samples were immediately frozen in liquid nitrogen and stored at $80^{\circ} \mathrm{C}$ until RNA isolation.

\section{Gene model prediction and ORF verification.}

Protein sequences for two known NLP genes, PsNLP1 (PsojNIP) and PiNPP1.1, were obtained from GenBank with accession numbers AAM48170 and AY961417, respectively. Both sequences were used as queries to search for similar sequences in the P. sojae genome sequence assembly database V1.0 and $P$. sojae predicted transcript database, with $\mathrm{E}$ value cut-off $<$ $10^{-15}$. Similar NLP sequence hits together with flanking sequences (1,000 bp from each end) were also examined using gene prediction programs (GENSCAN). To distinguish pseudogenes and real genes and to verify real gene models, PCR was conducted using genomic DNA and cDNA as templates. Primers are listed in Supplementary Table S5. The PCR was performed with 30 cycles of $30 \mathrm{~s}$ at $94^{\circ} \mathrm{C}, 30 \mathrm{~s}$ at 55 to $60^{\circ} \mathrm{C}$ (depending on genes), and $60 \mathrm{~s}$ at $72^{\circ} \mathrm{C}$ and the PCR products were examined on an agarose gel. The genomic DNA of P. sojae was isolated from mycelium grown in 10\% V8 liquid medium by using a modified cetyltrimethylammonium bromide method (Murray and Thompson 1980). The cDNA library, containing approximately $10^{7} \mathrm{cDNA}$ clones, was a mixed library with $P$. sojae mycelium, zoospore, encysted zoospore, germinated zoospore, and infection stages (including 3, 6, 12, and $24 \mathrm{hpi}$ ). The cDNA library is technically supported by Invitrogen (Shanghai). For those NLP predicted with introns, PCR products from cDNAs were resequenced (Invitrogen sequence service, Shanghai).

\section{Real-time RT-PCR.}

To monitor NLP transcript profiling by real-time RT-PCR, total RNA samples from mycelia, zoospores, encysted zoospores, germinated cyst, and infected plant tissue samples were extracted using a total RNA isolation kit (PK701; SLN Inc., Shanghai). The first-strand cDNA was synthesized using Superscript II reverse transcriptase (Invitrogen) following the manufacturer's directions. For NLP transcript profiling analysis, SYBR green real-time RT-PCR assays were carried out. Primer pairs were designed specifically to each of the selected $P$. sojae NLP. Two constitutively expressed $P$. sojae genes were selected as controls, namely actin (Joint Genome Institute [JGI] gene ID 109046) and rpS5 (JGI gene ID 144810). PCR reactions $(20 \mu \mathrm{l})$ included $20 \mathrm{ng}$ of $\mathrm{cDNA}, 0.2 \mu \mathrm{M}$ each primer, and $10 \mu \mathrm{l}$ of SYBR Premix ExTaq (TaKaRa Inc., Dalian, China). Reactions were performed on an ABI PRISM 7300 fast real-time PCR system (Applied Biosystems, Foster City, CA, U.S.A.) under the following conditions: $95^{\circ} \mathrm{C}$ for $30 \mathrm{~s} ; 40$ cycles of $95^{\circ} \mathrm{C}$ for $5 \mathrm{~s}, 60^{\circ} \mathrm{C}$ for $31 \mathrm{~s}$; followed by $95^{\circ} \mathrm{C}$ for 15 $\mathrm{s}, 60^{\circ} \mathrm{C}$ for $1 \mathrm{~min}$, and then, $95^{\circ} \mathrm{C}$ for $15 \mathrm{~s}$ to obtain melt curves. The expression of each gene relative to average $\mathrm{Ct}$ values of the two control genes $\left(\mathrm{Ct}=\mathrm{Ct}_{\text {gene }}-\mathrm{Ct}_{\mathrm{HKaverage}}\right)$ was determined and analyzed by using the ABI 7300 System Sequence Detection Software, version 1.4 (Schuhmacher et al. 2010).

\section{Construction of recombinant $\boldsymbol{A}$. tumefaciens binary PVX vectors.}

Full-length (including signal peptide) NLP genes were PCR amplified from $P$. sojae P6497 genomic DNA using high-fidelity DNA polymerase (TaKaRa Inc.) with primers. All of the products showed clear bands on $0.8 \%$ agarose gel with the expected size. The PVX vector pGR107 (Jones et al. 1999) for plant transient expression assay was isolated by using a plasmid spin column-small isolation kit (PK301; SLN Inc.). Highfidelity PCR products were subcloned into pGR107 predigested by restrict enzyme SmaI. For chimeric constructs PSNLP1 $1_{\mathrm{sp}}:$ :
PsNLP11 $107-330$ and PsNLP1 $1_{\text {sp }}:$ PsNLP59 ${ }_{113-334}$, fragments PsNLP11 $107-330$ and PsNLP59 ${ }_{113-334}$ were PCR amplified and inserted into a pGR107::PsNLP1 $1_{\text {sp }}$ vector containing a 25amino-acid signal peptide from PsNLP1.

A forward primer (5'-CTTGTGTCATCAAGATTACTG-3') from pGR107 and NLP reverse primers were used to identify recombinant clones with correct insert orientation. Plasmids from selected Escherichia coli clones were purified for DNA sequencing. Recombinant binary vectors were maintained and propagated in E. coli JM109, grown in the presence of kanamycin at $50 \mathrm{mg} / \mathrm{ml}$. The recombinant binary vectors were transformed into A. tumefaciens GV3101 by electroporation. After growing at $28^{\circ} \mathrm{C}$ in Luria-Bertani (LB) agar plates supplemented with kanamycin at $50 \mathrm{mg} / \mathrm{ml}$ as selective agents for 2 days, individual $A$. tumefaciens colonies were extracted with $\mathrm{NaOH}(2 \mathrm{mM})$ lysis solution and PCR amplified to verify that the correct clones were selected for plant transient expression assay.

\section{Agrobacterium sp.-mediated plant transient expression.}

A. tumefaciens strains carrying candidate NLP genes were grown in LB broth cultures supplemented with kanamycin at $25 \mathrm{mg} / \mathrm{ml}$ for 1 day at $28^{\circ} \mathrm{C}$ with constant shaking. The cultures were centrifuged $10,000 \times g$ for $1 \mathrm{~min}$ in a tabletop centrifuge. The pellet was resuspended in $1 \mathrm{ml}$ of induction medium $(10$ $\mathrm{mM}$ MES, $10 \mathrm{mM} \mathrm{MgCl}$, and $150 \mathrm{mM}$ acetosyringone, $\mathrm{pH}$ 5.6). The final concentration of Agrobacterium cultures were measured and adjusted with induction medium to an optical density at $600 \mathrm{~nm}$ of 0.4 and young $N$. benthamiana leaves were infiltrated with Agrobacterium cultures using a blunt syringe (Oh et al. 2009). The development of disease symptoms was recorded for up to 10 days after the plant was infiltrated by Agrobacterium cultures. All of the Agrobacterium infiltration experiments have been repeated at least eight times. Agrobacterium spp. harboring green fluorescent protein and INF1 (Kamoun et al. 1997) was used as negative and positive control in our experiments. Our results for PSNLP1 and INF1 agroinfiltration in $N$. benthamiana each show a strong necrotic response, consistent with previous data (Kamoun et al. 1997; Qutob et al. 2002).

\section{Protein extraction and Western blot.}

$N$. benthamiana total protein was extracted by grinding 400 $\mathrm{mg}$ of leaf tissue in $1 \mathrm{ml}$ of extraction buffer $(50 \mathrm{mM}$ Tris, $\mathrm{pH}$ $7.4 ; 150 \mathrm{mM} \mathrm{NaCl}$; and $1 \%$ Triton $\mathrm{X}-100)$ in the presence of 5 $\mu \mathrm{l}$ of protease inhibitor cocktail (P9599; Sigma-Aldrich, St. Louis). Total protein extract samples were loaded on sodium dodecyl sulfate polyacrylamide gel electrophoresis gel using equivalent amounts of protein for each sample in an experiment. After electrophoresis, proteins were transferred from gel to polyvinylidene diflouride membrane. Western blotting was performed as previously described (Wang et al. 2011). Mouse anti-HA monoclonal antibody (Sigma-Aldrich) and goat antimouse immunoglobulin G-peroxidase conjugate (SigmaAldrich) were used as the primary and secondary antibodies. The membrane was treated with chemiluminescent peroxidase substrate 1 (number 34080; Thermo Scientific Pierce, Rockford, IL, U.S.A.) for $2 \mathrm{~min}$. The membrane was briefly drained and exposed to BioMax (Kodak, Rochester, NY, U.S.A.) light film several times (depending on results) for exposure signal development.

\section{Sequence analysis.}

For 33 predicted real NLP genes, nucleotide sequences were aligned using ClustalW and analyzed for phylogenetic and molecular evolutionary relationships using MEGA4 software (Tamura et al. 2007). A bootstrap consensus tree was made by 
using the neighbor-joining method with the Kimura-2 nucleotide model and the bootstrap value was set at 1,000 replicates. The protein sequences of these NLP were submitted to SignalPv3.0 for secreted signal peptide prediction. Protein domain and motif analysis was conducted using the NCBI conserved domain database Motif Scan. Protein sequence multiple alignment was conducted by using BioEdit 2005. Conserved GHRHDWE heptapeptide motif and key residues responsible for necrosis activity were identified based on previous reports (Gijzen and Nurnberger 2006; Ottmann et al. 2009).

\section{PAML analysis, positive selection test, and residue mapping.}

In total, 99 real NLP ortholog sequences from three distinct P. sojae strains (P7064, P7074, and P7076) were collected from the Virginia Bioinformatics Institute 454 P. sojae genome sequence database. The PsNLP1 (PsojNIP) orthologous sequences were download from NCBI and JGI. All of these nucleotide sequences, together with 33 real NLP sequences from the standard P. sojae P6497, are listed in Supplementary Table S4. The ML method using the computer program codeml from the PAML 4.2a package (Yang 2007) was used to conduct positive selection analysis, according to procedures previously described (Liu et al. 2005; Win et al. 2007). Codon substitution model M8 was allowed for heterogeneous selection pressures across codon sites, while the null model M7 only allowed ratio classes with $\omega<1$. Statistical significance was tested by comparing the null model M7 with the alternative model M8 using an LRT. Twice the difference in log likelihood ratio was compared with a $\chi^{2}$ distribution with two degrees of freedom. The positively selected sites in tested NLP were identified using the Bayes Empirical Bayes analysis implemented in codeml (Yang et al. 2005). The NLP surface model (Potato Data Bank ID 3GNU) was shown by using PyMOL software. Residues were highlighted according to PyMOL manual.

\section{ACKNOWLEDGMENTS}

This work was supported by the Special Fund for Agro-scientific Research in the Public Interest (3-20) from China to Y.-C. Wang, by a project funded by the Priority Academic Program Development of Jiangsu Higher Education Institutions. We thank B. Tyler (Oregon State University, U.S.A.) for sharing 454 sequencing data for P. sojae strains; Z. Zhang (Nanjing Agricultural University, China) for sharing plant transient expression experience; X. Tao (Nanjing Agricultural University, China) for helping protein structure analysis; S. Yang (Nanjing University, China) for helpful suggestions in positive selection tests; and W. Ye, J. Li, and W. Yin (Nanjing Agricultural University, China) for DNA sequence analysis and plant care.

\section{LITERATURE CITED}

Amsellem, Z., Cohen, B. A., and Gressel, J. 2002. Engineering hypervirulence in a mycoherbicidal fungus for efficient weed control. Nat. Biotechnol. 20:1035-1039.

Armstrong, M. R., Whisson, S. C., Pritchard, L., Bos, J. I., Venter, E., Avrova, A. O., Rehmany, A. P., Bohme, U., Brooks, K., Cherevach, I., Hamlin, N., White, B., Fraser, A., Lord, A., Quail, M. A., Churcher, C., Hall, N., Berriman, M., Huang, S., Kamoun, S., Beynon, J. L., and Birch, P. R. 2005. An ancestral oomycete locus contains late blight avirulence gene Avr3a, encoding a protein that is recognized in the host cytoplasm. Proc. Natl. Acad. Sci. U.S.A. 102:7766-7771.

Bae, H., Bowers, J. H., Tooley, P. W., and Bailey, B. A. 2005. NEP1 orthologs encoding necrosis and ethylene inducing proteins exist as a multigene family in Phytophthora megakarya, causal agent of black pod disease on cacao. Mycol. Res. 109:1373-1385.

Bailey, B. A. 1995. Purification of a protein from culture filtrates of Fusarium oxysporum that induces ethylene and necrosis in leaves of Erythroxylum coca. Phytopathology 85:1250-1255.

Baxter, L., Tripathy, S., Ishaque, N., Boot, N., Cabral, A., Kemen, E.,
Thines, M., Ah-Fong, A., Anderson, R., Badejoko, W., Bittner-Eddy, P., Boore, J. L., Chibucos, M.C., Coates, M., Dehal, P., Delehaunty, K., Dong, S., Downton, P., Dumas, B., Fabro, G., Fronick, C., Fuerstenberg, S. I., Fulton, L., Gaulin, E., Govers, F., Hughes, L., Humphray, S., Jiang, R. H., Judelson, H., Kamoun, S., Kyung, K., Meijer, H., Minx, P., Morris, P., Nelson, J., Phuntumart, V., Qutob, D., Rehmany, A., RougonCardoso, A., Ryden, P., Torto-Alalibo, T., Studholme, D., Wang, Y., Win, J., Wood, J., Clifton, S. W., Rogers, J., Van den Ackerveken, G., Jones, J. D., McDowell, J. M., Beynon, J., and Tyler, B. M. 2010. Signatures of adaptation to obligate biotrophy in the Hyaloperonospora arabidopsidis genome. Science 330:1549-1551.

Bendtsen, J. D., Nielsen, H., von Heijne, G., and Brunak, S. 2004. Improved prediction of signal peptides: SignalP 3.0. J. Mol. Biol. 340:783-795

Cabral, A., Oome, S., Sander, N., Kuefner, I., Nurnberger, T., and Van den Ackerveken, G. 2012. Nontoxic Nep1-like proteins of the downy mildew pathogen Hyaloperonospora arabidopsidis: Repression of necrosis-inducing activity by a surface-exposed region. Mol. Plant-Microbe Interact. 25:697-708

Dallal Bashi, Z., Hegedus, D. D., Buchwaldt, L., Rimmer, S. R., and Borhan, M. H. 2010. Expression and regulation of Sclerotinia sclerotiorum necrosis and ethylene-inducing peptides (NEPs). Mol. Plant Pathol. 11:43-53.

Dong, S., Qutob, D., Tedman-Jones, J., Kuflu, K., Wang, Y., Tyler, B. M., and Gijzen, M. 2009. The Phytophthora sojae avirulence locus Avr3c encodes a multi-copy RXLR effector with sequence polymorphisms among pathogen strains. PLoS One 4:e5556.

Dong, S., Yin, W., Kong, G., Yang, X., Qutob, D., Chen, Q., Kale, S. D., Sui, Y., Zhang, Z., Dou, D., Zheng, X., Gijzen, M., B, M. T., and Wang, Y. 2011a. Phytophthora sojae avirulence effector Avr3b is a secreted $\mathrm{NADH}$ and ADP-ribose pyrophosphorylase that modulates plant immunity. PLoS Pathog. 7:e1002353. Published online.

Dong, S., Yu, D., Cui, L., Qutob, D., Tedman-Jones, J., Kale, S. D., Tyler, B. M., Wang, Y., and Gijzen, M. 2011b. Sequence variants of the Phytophthora sojae RXLR effector Avr3a/5 are differentially recognized by Rps3a and Rps5 in soybean. PLoS One 6:e20172. Published online.

Dou, D., Kale, S. D., Wang, X., Chen, Y., Wang, Q., Jiang, R. H., Arredondo, F. D., Anderson, R. G., Thakur, P. B., McDowell, J. M., Wang, Y., and Tyler, B. M. 2008. Conserved C-terminal motifs required for avirulence and suppression of cell death by Phytophthora sojae effector Avr1b. Plant Cell 20:1118-1133.

Dou, D., Kale, S. D., Liu, T., Tang, Q., Wang, X., Arredondo, F. D., Basnayake, S., Whisson, S., Drenth, A., Maclean, D., and Tyler, B. M. 2010. Different domains of Phytophthora sojae effector Avr4/6 are recognized by soybean resistance genes Rps4 and Rps6. Mol. PlantMicrobe Interact. 23:425-435.

Fellbrich, G., Romanski, A., Varet, A., Blume, B., Brunner, F., Engelhardt, S., Felix, G., Kemmerling, B., Krzymowska, M., and Nurnberger, T. 2002. NPP1, a Phytophthora-associated trigger of plant defense in parsley and Arabidopsis. Plant J. 32:375-390.

Garcia, O., Macedo, J. A., Tiburcio, R., Zaparoli, G., Rincones, J., Bittencourt, L. M., Ceita, G. O., Micheli, F., Gesteira, A., Mariano, A. C., Schiavinato, M. A., Medrano, F. J., Meinhardt, L. W., Pereira, G.A., and Cascardo, J. C. 2007. Characterization of necrosis and ethyleneinducing proteins (NEP) in the basidiomycete Moniliophthora perniciosa, the causal agent of witches' broom in Theobroma cacao. Mycol. Res. 111:443-455.

Gaulin, E., Jauneau, A., Villalba, F., Rickauer, M., Esquerre-Tugaye, M. T., and Bottin, A. 2002. The CBEL glycoprotein of Phytophthora parasitica var. nicotianae is involved in cell wall deposition and adhesion to cellulosic substrates. J. Cell Sci. 115:4565-4575.

Gaulin, E., Drame, N., Lafitte, C., Torto-Alalibo, T., Martinez, Y., AmelineTorregrosa, C., Khatib, M., Mazarguil, H., Villalba-Mateos, F., Kamoun, S., Mazars, C., Dumas, B., Bottin, A., Esquerre-Tugaye, M. T., and Rickauer, M. 2006. Cellulose binding domains of a Phytophthora cell wall protein are novel pathogen-associated molecular patterns. Plant Cell 18:1766-1777.

Gijzen, M., and Nurnberger, T. 2006. Nep1-like proteins from plant pathogens: Recruitment and diversification of the NPP1 domain across taxa. Phytochemistry 67:1800-1807.

Gilroy, E. M., Breen, S., Whisson, S. C., Squires, J., Hein, I., Kaczmarek, M., Turnbull, D., Boevink, P. C., Lokossou, A., Cano, L. M., Morales, J., Avrova, A. O., Pritchard, L., Randall, E., Lees, A., Govers, F., van West, P., Kamoun, S., Vleeshouwers, V. G., Cooke, D. E., and Birch, P. R. Presence/absence, differential expression and sequence polymorphisms between PiAVR2 and PiAVR2-like in Phytophthora infestans determine virulence on R2 plants. New Phytol. 191:763-776.

Haas, B. J., Kamoun, S., Zody, M. C., Jiang, R. H., Handsaker, R. E. Cano, L. M., Grabherr, M., Kodira, C. D., Raffaele, S., Torto-Alalibo, T., Bozkurt, T. O., Ah-Fong, A. M., Alvarado, L., Anderson, V. L., 
Armstrong, M. R., Avrova, A., Baxter, L., Beynon, J., Boevink, P. C. Bollmann, S. R., Bos, J. I., Bulone, V., Cai, G., Cakir, C., Carrington, J. C., Chawner, M., Conti, L., Costanzo, S., Ewan, R., Fahlgren, N., Fischbach, M. A., Fugelstad, J., Gilroy, E. M., Gnerre, S., Green, P. J., Grenville-Briggs, L. J., Griffith, J., Grunwald, N. J., Horn, K., Horner, N. R., Hu, C. H., Huitema, E., Jeong, D. H., Jones, A. M., Jones, J. D., Jones, R. W., Karlsson, E. K., Kunjeti, S. G., Lamour, K., Liu, Z., Ma, L., Maclean, D., Chibucos, M. C., McDonald, H., McWalters, J., Meijer, H. J., Morgan, W., Morris, P. F., Munro, C. A., O'Neill, K., OspinaGiraldo, M., Pinzon, A., Pritchard, L., Ramsahoye, B., Ren, Q., Restrepo, S., Roy, S., Sadanandom, A., Savidor, A., Schornack, S., Schwartz, D. C., Schumann, U. D., Schwessinger, B., Seyer, L., Sharpe, T., Silvar, C., Song, J., Studholme, D. J., Sykes, S., Thines, M., van de Vondervoort, P. J., Phuntumart, V., Wawra, S., Weide, R., Win, J., Young, C., Zhou, S., Fry, W., Meyers, B. C., van West, P., Ristaino, J., Govers, F., Birch, P. R., Whisson, S. C., Judelson, H. S., and Nusbaum, C. 2009. Genome sequence and analysis of the Irish potato famine pathogen Phytophthora infestans. Nature 461:393-398.

Hua, C., Wang, Y., Zheng, X., Dou, D., Zhang, Z., and Govers, F. 2008. A Phytophthora sojae G-protein alpha subunit is involved in chemotaxis to soybean isoflavones. Eukaryot. Cell 7:2133-2140.

Jiang, R. H., Dawe, A. L., Weide, R., van Staveren, M., Peters, S., Nuss, D. L., and Govers, F. 2005. Elicitin genes in Phytophthora infestans are clustered and interspersed with various transposon-like elements. Mol. Genet. Genomics 273:20-32.

Jiang, R. H., Tyler, B. M., and Govers, F. 2006a. Comparative analysis of Phytophthora genes encoding secreted proteins reveals conserved synteny and lineage-specific gene duplications and deletions. Mol. Plant-Microbe Interact. 19:1311-1321.

Jiang, R. H., Tyler, B. M., Whisson, S. C., Hardham, A. R., and Govers, F. 2006b. Ancient origin of elicitin gene clusters in Phytophthora genomes. Mol. Biol. Evol. 23:338-351.

Jones, J. D., and Dangl, J. L. 2006. The plant immune system. Nature 444:323-329.

Jones, L., Hamilton, A. J., Voinnet, O., Thomas, C. L., Maule, A. J., and Baulcombe, D. C. 1999. RNA-DNA interactions and DNA methylation in post-transcriptional gene silencing. Plant Cell 11:2291-2301.

Kamoun, S. 2006. A catalogue of the effector secretome of plant pathogenic oomycetes. Annu. Rev. Phytopathol. 44:41-60.

Kamoun, S., van West, P., de Jong, A. J., de Groot, K. E., Vleeshouwers, V. G., and Govers, F. 1997. A gene encoding a protein elicitor of Phytophthora infestans is down-regulated during infection of potato. Mol. Plant-Microbe Interact. 10:13-20.

Kanneganti, T. D., Huitema, E., Cakir, C., and Kamoun, S. 2006. Synergistic interactions of the plant cell death pathways induced by Phytophthora infestans Nepl-like protein PiNPP1.1 and INF1 elicitin. Mol. Plant-Microbe Interact. 19:854-863.

Kelley, B. S., Lee, S. J., Damasceno, C. M., Chakravarthy, S., Kim, B. D., Martin, G. B., and Rose, J. K. 2010. A secreted effector protein (SNE1) from Phytophthora infestans is a broadly acting suppressor of programmed cell death. Plant J. 62:357-366.

Levesque, C. A., Brouwer, H., Cano, L., Hamilton, J. P., Holt, C., Huitema, E., Raffaele, S., Robideau, G. P., Thines, M., Win, J., Zerillo, M. M., Beakes, G. W., Boore, J. L., Busam, D., Dumas, B., Ferriera, S., Fuerstenberg, S. I., Gachon, C. M., Gaulin, E., Govers, F., GrenvilleBriggs, L., Horner, N., Hostetler, J., Jiang, R. H., Johnson, J., Krajaejun, T., Lin, H., Meijer, H. J., Moore, B., Morris, P., Phuntmart, V., Puiu, D., Shetty, J., Stajich, J. E., Tripathy, S., Wawra, S., van West, P., Whitty, B. R., Coutinho, P. M., Henrissat, B., Martin, F., Thomas, P. D., Tyler, B. M., De Vries, R. P., Kamoun, S., Yandell, M., Tisserat, N., and Buell, C. R. 2010. Genome sequence of the necrotrophic plant pathogen Pythium ultimum reveals original pathogenicity mechanisms and effector repertoire. Genome Biol. 11:R73.

Liu, Z., Bos, J. I., Armstrong, M., Whisson, S. C., da Cunha, L., TortoAlalibo, T., Win, J., Avrova, A. O., Wright, F., Birch, P. R., and Kamoun, S. 2005. Patterns of diversifying selection in the phytotoxin-like scr74 gene family of Phytophthora infestans. Mol. Biol. Evol. 22:659-672.

Mattinen, L., Tshuikina, M., Mae, A., and Pirhonen, M. 2004. Identification and characterization of Nip, necrosis-inducing virulence protein of Erwinia carotovora subsp. carotovora. Mol. Plant-Microbe Interact. 17:1366-1375.

Motteram, J., Kufner, I., Deller, S., Brunner, F., Hammond-Kosack, K. E., Nurnberger, T., and Rudd, J. J. 2009. Molecular characterization and functional analysis of MgNLP, the sole NPP1 domain-containing protein, from the fungal wheat leaf pathogen Mycosphaerella graminicola. Mol. Plant-Microbe Interact. 22:790-799.

Murray, M. G., and Thompson, W. F. 1980. Rapid isolation of high molecular weight plant DNA. Nucleic Acids Res. 8:4321-4325.

Oh, S. K., Young, C., Lee, M., Oliva, R., Bozkurt, T. O., Cano, L. M., Win, J., Bos, J. I., Liu, H. Y., van Damme, M., Morgan, W., Choi, D., Van der
Vossen, E. A., Vleeshouwers, V. G., and Kamoun, S. 2009. In planta expression screens of Phytophthora infestans RXLR effectors reveal diverse phenotypes, including activation of the Solanum bulbocastanum disease resistance protein Rpi-blb2. Plant Cell 21:2928-2947.

Oliva, R., Win, J., Raffaele, S., Boutemy, L., Bozkurt, T. O., ChaparroGarcia, A., Segretin, M. E., Stam, R., Schornack, S., Cano, L. M., van Damme, M., Huitema, E., Thines, M., Banfield, M. J., and Kamoun, S. 2010. Recent developments in effector biology of filamentous plant pathogens. Cell Microbiol. 12:1015.

Ottmann, C., Luberacki, B., Kufner, I., Koch, W., Brunner, F., Weyand, M., Mattinen, L., Pirhonen, M., Anderluh, G., Seitz, H. U., Nurnberger, T., and Oecking, C. 2009. A common toxin fold mediates microbial attack and plant defense. Proc. Natl. Acad. Sci. U.S.A. 106:10359-10364.

Pemberton, C. L., and Salmond, G. P. 2004. The Nep1-like proteins-A growing family of microbial elicitors of plant necrosis. Mol. Plant Pathol. 5:353-359.

Pemberton, C. L., Whitehead, N. A., Sebaihia, M., Bell, K. S., Hyman, L. J., Harris, S. J., Matlin, A. J., Robson, N. D., Birch, P. R., Carr, J. P. Toth, I. K., and Salmond, G. P. 2005. Novel quorum-sensing-controlled genes in Erwinia carotovora subsp. carotovora: Identification of a fungal elicitor homologue in a soft-rotting bacterium. Mol. Plant-Microbe Interact. 18:343-353

Qutob, D., Hraber, P. T., Sobral, B. W., and Gijzen, M. 2000. Comparative analysis of expressed sequences in Phytophthora sojae. Plant Physiol. 123:243-254.

Qutob, D., Kamoun, S., and Gijzen, M. 2002. Expression of a Phytophthora sojae necrosis-inducing protein occurs during transition from biotrophy to necrotrophy. Plant J. 32:361-373.

Qutob, D., Kemmerling, B., Brunner, F., Kufner, I., Engelhardt, S., Gust, A.A., Luberacki, B., Seitz, H.U., Stahl, D., Rauhut, T., Glawischnig, E., Schween, G., Lacombe, B., Watanabe, N., Lam, E., Schlichting, R., Scheel, D., Nau, K., Dodt, G., Hubert, D., Gijzen, M., and Nurnberger, T. 2006. Phytotoxicity and innate immune responses induced by Nep1like proteins. Plant Cell 18:3721-3744.

Qutob, D., Tedman-Jones, J., Dong, S., Kuflu, K., Pham, H., Wang, Y., Dou, D., Kale, S. D., Arredondo, F. D., Tyler, B. M., and Gijzen, M. 2009. Copy number variation and transcriptional polymorphisms of Phytophthora sojae RXLR effector genes Avr1a and Avr3a. PLoS One 4:e5066.

Robold, A. V., and Hardham, A. R. 2005. During attachment Phytophthora spores secrete proteins containing thrombospondin type 1 repeats. Curr. Genet. 47:307-315.

Schouten, A., van Baarlen, P., and van Kan, J. A. 2008. Phytotoxic Nep1like proteins from the necrotrophic fungus Botrytis cinerea associate with membranes and the nucleus of plant cells. New Phytol. 177:493505 .

Schuhmacher, T., Lemuth, K., Hardiman, T., Vacun, G., Reuss, M., and Siemann-Herzberg, M. 2010. Quantifying cytosolic messenger RNA concentrations in Escherichia coli using real-time polymerase chain reaction for a systems biology approach. Anal. Biochem. 398:212-217.

Shan, W., Cao, M., Leung, D., and Tyler, B. M. 2004. The Avr1b locus of Phytophthora sojae encodes an elicitor and a regulator required for avirulence on soybean plants carrying resistance gene Rps1b. Mol. Plant-Microbe Interact. 17:394-403.

Staats, M., van Baarlen, P., Schouten, A., and van Kan, J. A. 2007a. Functional analysis of NLP genes from Botrytis elliptica. Mol. Plant Pathol. 8:209-214

Staats, M., van Baarlen, P., Schouten, A., van Kan, J. A., and Bakker, F. T. 2007b. Positive selection in phytotoxic protein-encoding genes of Botrytis species. Fungal Genet. Biol. 44:52-63.

Tamura, K., Dudley, J., Nei, M., and Kumar, S. 2007. MEGA4: Molecular Evolutionary Genetics Analysis (MEGA) software version 4.0. Mol. Biol. Evol. 24:1596-1599.

Torto, T. A., Li, S., Styer, A., Huitema, E., Testa, A., Gow, N. A., van West, P., and Kamoun, S. 2003. EST mining and functional expression assays identify extracellular effector proteins from the plant pathogen Phytophthora. Genome Res. 13:1675-1685.

Tyler, B. M., Tripathy, S., Zhang, X., Dehal, P., Jiang, R. H., Aerts, A., Arredondo, F. D., Baxter, L., Bensasson, D., Beynon, J. L., Chapman, J., Damasceno, C. M., Dorrance, A. E., Dou, D., Dickerman, A. W., Dubchak, I. L., Garbelotto, M., Gijzen, M., Gordon, S. G., Govers, F., Grunwald, N. J., Huang, W., Ivors, K. L., Jones, R. W., Kamoun, S., Krampis, K., Lamour, K. H., Lee, M. K., McDonald, W. H., Medina, M., Meijer, H. J., Nordberg, E. K., Maclean, D. J., Ospina-Giraldo, M. D., Morris, P. F., Phuntumart, V., Putnam, N. H., Rash, S., Rose, J. K. Sakihama, Y., Salamov, A. A., Savidor, A., Scheuring, C. F., Smith, B. M., Sobral, B. W., Terry, A., Torto-Alalibo, T. A., Win, J., Xu, Z., Zhang, H., Grigoriev, I. V., Rokhsar, D. S., and Boore, J. L. 2006. Phytophthora genome sequences uncover evolutionary origins and mechanisms of pathogenesis. Science 313:1261-1266. 
van Poppel, P. M., Guo, J., van de Vondervoort, P. J., Jung, M. W., Birch, P. R., Whisson, S. C., and Govers, F. 2008. The Phytophthora infestans avirulence gene Avr4 encodes an RXLR-dEER effector. Mol. PlantMicrobe Interact. 21:1460-1470.

Vleeshouwers, V. G., Rietman, H., Krenek, P., Champouret, N., Young, C., Oh, S. K., Wang, M., Bouwmeester, K., Vosman, B., Visser, R. G., Jacobsen, E., Govers, F., Kamoun, S., and Van der Vossen, E. A. 2008. Effector genomics accelerates discovery and functional profiling of potato disease resistance and Phytophthora infestans avirulence genes. PLoS One 3:e2875

Wang, J. Y., Cai, Y., Gou, J. Y., Mao, Y. B., Xu, Y. H., Jiang, W. H., and Chen, X. Y. 2004. VdNEP, an elicitor from Verticillium dahliae, induces cotton plant wilting. Appl. Environ. Microbiol. 70:4989-4995.

Wang, Q., Han, C., Ferreira, A. O., Ye, W., Tripathy, S., Kale, S. D., Gu, B., Wang, X., Yu, X., Liu, T., Yao, Y., Wang, X., Sheng, Y., Sui, Y., Zhang, Z., Cheng, B., Dong, S., Shan, W., Zheng, X., Dou, D., Tyler, B. M., and Wang., Y. 2011. Transcriptional programming and functional interactions within the Phytophthora sojae RXLR effector repertoire. Plant Cell 23:2064-2086.

Win, J., Morgan, W., Bos, J., Krasileva, K. V., Cano, L. M., ChaparroGarcia, A., Ammar, R., Staskawicz, B. J., and Kamoun, S. 2007. Adaptive evolution has targeted the C-terminal domain of the RXLR effectors of plant pathogenic oomycetes. Plant Cell 19:2349-2369.

Yang, Z. 2007. PAML 4: Phylogenetic analysis by maximum likelihood. Mol. Biol. Evol. 24:1586-1591.

Yang, Z., Wong, W. S., and Nielsen, R. 2005. Bayes empirical Bayes inference of amino acid sites under positive selection. Mol. Biol. Evol. 22:1107-1118

Ye, W., Wang, X., Tao, K., Lu, Y., Dai, T., Dong, S., Dou, D., Gijzen, M., and Wang, Y. 2011. Digital gene expression profiling of the Phytophthora sojae transcriptome. Mol. Plant-Microbe Interact. 24:1530-1539.

\section{AUTHOR-RECOMMENDED INTERNET RESOURCES}

Center for Biological Sequence Analysis prediction servers: www.cbs.dtu.dk/service

The GENSCAN Web server at MIT: genes.mit.edu/GENSCAN.html

JGI Tre of Life webpage: genome.jgi-psf.org

VBI Microbial database: vmd.vbi.vt.edu/toolkit

MyHits Motif Scan: myhits.isb-sib.ch/cgi-bin/motif_scan

NCBI Conserved Domains and Protein Classification database: www.ncbi.nlm.nih.gov/Structure/cdd/cdd.shtml

Protein Data: www.rcsb.org 